\title{
Electron transport phenomena of electroactive bacteria in microbial fuel cells: a review of Proteus hauseri
}

\author{
I-Son Ng ${ }^{1 *} \mathbb{D}$, Chung-Chuan Hsueh ${ }^{2}$ and Bor-Yann Chen ${ }^{2^{*}}$
}

\begin{abstract}
This review tended to decipher the expression of electron transfer capability (e.g., biofilm formation, electron shuttles, swarming motility, dye decolorization, bioelectricity generation) to microbial fuel cells (MFCs). As mixed culture were known to perform better than pure microbial cultures for optimal expression of electrochemically stable activities to pollutant degradation and bioenergy recycling, Proteus hauseri isolated as a "keystone species" to maintain such ecologically stable potential for power generation in MFCs was characterized. P. hauseri expressed outstanding performance of electron transfer (ET)-associated characteristics [e.g., reductive decolorization (RD) and bioelectricity generation (BG)] for electrochemically steered bioremediation even though it is not a nanowire-generating bacterium. This review tended to uncover taxonomic classification, genetic or genomic characteristics, enzymatic functions, and bioelectricity-generating capabilities of Proteus spp. with perspectives for electrochemical practicability. As a matter of fact, using MFCs as a tool to evaluate ET capabilities, dye decolorizer(s) could clearly express excellent performance of simultaneous bioelectricity generation and reductive decolorization (SBG and RD) due to feedback catalysis of residual decolorized metabolites (DMs) as electron shuttles (ESs). Moreover, the presence of reduced intermediates of nitroaromatics or DMs as ESs could synergistically augment efficiency of reductive decolorization and power generation. With swarming mobility, P. hauseri could own significant biofilm-forming capability to sustain ecologically stable consortia for RD and BG. This mini-review evidently provided lost episodes of great significance about bioenergysteered applications in myriads of fields (e.g., biodegradation, biorefinery, and electro-fermentation).
\end{abstract}

Keywords: Proteus hauseri, Reductive decolorization, Bioelectricity generation, Bioremediation

\section{Introduction}

This review tended to disclose unsolved mysteries of electron transfer phenomena for biomass energy applications with sustainability. Faced with increasingly scarce supply of energy and resources and gradually serious threats of ecological deprivation around the globe, top governing bodies of various nations have pushed forward with efforts for environmental decontamination and materials/energy renewability of the vulnerable ecology. That is,

\footnotetext{
*Correspondence: yswu@mail.ncku.edu.tw; bychen@niu.edu.tw; boryannchen@yahoo.com.tw

${ }^{1}$ Department of Chemical Engineering, National Cheng Kung University, Tainan 70101, Taiwan

${ }^{2}$ Department of Chemical and Materials Engineering, National I-Lan University, I-Lan 26047, Taiwan
}

with strict measures for energy conservation and emission reduction, environmental/ecological protection/ prevention and materials/energy recycling/reuses are of great importance to this resource-limited world. Making use of innovative features and environmental benefits of sustainable biomass energy extraction for applications would be inevitable. As a matter of fact, microbial fuel cells (MFCs) are bioelectrochemical devices that use electroactive microbes and mimicked bacterial interactions as biocatalysts to drive current of bioenergy from oxidation of organics for bioelectricity generation and wastewater treatment (Logan et al. 2006; Ren et al. 2012; Pant et al. 2010; Rabaey and Verstraete 2005; Rozendal et al. 2008, 2009). MFCs apparently would be promising platform to evaluate feasibility of bioresources for 
biorefinery/bioenergy practicability. At ambient temperature, anodic bacteria oxidize organic matter with direct current production for $\mathrm{CO}_{2}$ production and pollutant decontamination. Meanwhile, protons migrated through separation of an ion exchange membrane (e.g., proton exchange membrane) toward cathode and electrons went through external circuit to the cathode simultaneously. Then, bioelectricity generation would be taken place at (bio)cathode coupled with water formation (i.e., $\frac{1}{2} \mathrm{O}_{2}+2 \mathrm{H}^{+}+2 \mathrm{e}^{-} \rightarrow \mathrm{H}_{2} \mathrm{O}$ ). In fact, there were at least several mechanisms in levels of genomics and proteomics for biofilm formation, direct electron transfer, mediator electron transport, and direct interspecies electron transfer dealing with performance of power generation in MFCs (Kumar et al. 2016). Regarding (bio)cathode, selecting appropriate electron acceptor could significantly attenuate the potential loss present on the cathode, effectively augmenting power generation in MFCs (He et al. 2015). Moreover, comparative assessment upon various electron acceptors popularly used in MFCs was also identified. As biocatalysts, exoelectrogenic bacteria are capable to directly transport electrons from extracellular media that enable bacterial cells function in an MFC. Therefore, the electrons produced by oxidation via microbial metabolism are transported through the barriers of biofilm-and-liquid interface, anodic immobilized cells, and solid anode, external circuit to the cathode for effective power generation or further applications (Mohan et al. 2014; ElMekawy et al. 2014). To overcome interphase electron transfer resistance and significantly augment electron flux across the boundary layer on the anodic surface, effective concentrations of biologically secreted or artificially synthesized exogenous mediators (e.g., flavins, pyocyanin, gallic acid and aminophenol, decolorized amines, polyphenolics; Chen et al. 2017a, b; Qin et al. 2016) in extracellular broth media and redoxactive complexes (e.g., $\mathrm{C}$ type cytochrome) across the outer membrane of microorganisms apparently play crucial roles to attenuate electron transfer resistance across different media interfaces or phases for effective power generation. Exogenous mediators as "electrochemical catalysts" could shuttle electrons to the electrode surface or to electron acceptors or donors if appropriate environmental conditions were provided (e.g., suitable pHs, redox potentials; Chen et al. 2017a). In particular, with assistance of electron shuttles (e.g., $o$ - and $p$-aminophenol, humic acid, methyl viologen, neutral red), electron transfer from electrochemically inactive bacteria (e.g., Escherichia coli) to the electrode might be effectively facilitated to be mediator MFCs. In contrast, due to self-secreted ESs (e.g., riboflavin, pyocyanin), electrochemically active bacteria-inoculated microbial communities could be successfully acclimatized as anodophilic consortia to transfer electrons to the cathode in mediator-free environments. That is, appropriate exogenous supplementation or intracellular accumulation of redox mediators all could significantly increase fluxes of electron transfer to simultaneously augment reductive degradation and bioelectricity generation. That is, electron shuttles might somehow still act as catalytic center of mediating electric current in electroactive bacteriabearing MFCs.

Regarding electrochemically active bacteria, species of genus Bacillus (Nimje et al. 2009), Enterobacter (Rezaei et al. 2009), Geobacter (Richter et al. 2008), Proteus (Chen et al. 1999), Shewanella (Watson and Logan 2010) have been explored to present practicability for bioelectricity generation. However, compared to pure microbial culture MFCs, mixed culture still exhibited the most promising stable power generation for longterm operation (Hassan et al. 2017; Ishii et al. 2017). In addition, synergistic interactions of mixed microbial communities in MFCs for long-term ecologically stable electrochemical expression could be sustained due to nutrient adaptability, stress resistance, degradation cooperation, in particular under fluctuating pollutant threat to species survival. For example, as Chen et al. (2004) and Chen (2007) indicated, due to the presence of toxic pollutants (e.g., textile dyes), mixed communities would not follow characteristics under competitive exclusion principle (or Gause's law), evolving to be in cooperation for maximal species richness and evenness (Chen 2007; Chen and Chang 2007). This is why in MFCs pure microbial culture of superstar electrochemically active bacteria (e.g., Shewanella and Geobacter) would very likely not perform better than mixed culture. As a matter of fact, several thorough studies using mixed cultures (Chen et al. 2004; Chen 2007; Chen and Chang 2007) all pointed out cooperative not competitive characteristics to maximize species diversity were the most ecologically stable strategy in face of pollutant threat for "survival to the fittest." In particular, regarding reductive decolorization and bioelectricity generation (Sun et al. 2009, 2011), decolorized metabolites (e.g., aromatic amines; Chen et al. 2011a, 2011b) identified as redox mediators via GC-MS analysis played a crucial role to stimulate operation performance (ca. $40-70 \%$ increases in electron transfer capabilities of MFCs; Han et al. 2015). In fact, several reviews have focused on different perspectives of MFCs in terms of basic principles and fundamental practices. However, a comprehensive review to exhibit such lost episodes on electron shuttles in particular used in MFCs is still lacking. Therefore, this review amended such last pieces of the puzzle in MFCs that have been ignored in recent years for clarification. 
Considering exoelectrogens for promising adaptation to bioremediation indigenous microbes were first selected to acclimatize from soils and water of contaminated sites. Then, selection pressure would be applied for induced biodegradation if appropriate actions of transformation enzymes could be effectively expressed (e.g., Chen et al. 1995, 2000). For instance, azo dye-bearing effluents from textile dyeing industry could significantly affect water quality in environment due to relatively low biodegradability of textile dyes $\left(\mathrm{ca} . \mathrm{BOD}_{5} / \mathrm{COD} \sim 0.2-\right.$ 0.5 ). To effectively biodegrade such pollutants, fungi, yeast, bacteria, algae, and plants were mentioned to be used (Saratale et al. 2011). Moreover, with electrontransfer-assisted treatment for green sustainability alternatives to combine with perspectives of dye degradation and energy/material recycling were recently suggested (Solanki et al. 2013). Azo dyes should be first anaerobically reduced to form aromatic amines. Next, aerobic degradation or complete mineralization could be proceeding. Azo linkages $(-\mathrm{N}=\mathrm{N}-)$ usually own sulphonic $\left(\mathrm{SO}_{3}{ }^{-}\right)$electron-withdrawing groups and thus are electron deficient; thus, they should be effectively reduced in the electron-acceptor- $\mathrm{O}_{2}$ absent conditions. Therefore, azo dye(s) with sulfonate groups and azo bond(s) strongly resist aerobic biodegradation. Apparently, azo bioreduction was taken place in different very different from oxidative degradation could be indicated $\left(\Phi_{1}\right.$ and $\Phi_{2}$ denoted aromatic compounds) as follows:

$\Phi_{1}-\mathrm{N}=\mathrm{N}-\Phi_{2}+4 \mathrm{H}^{+}+4 \mathrm{e}^{-} \rightarrow \Phi_{1}-\mathrm{NH}_{2}$

$+\Phi_{2}-\mathrm{NH}_{2}$ (reductive decolorization)

vs.

$\Phi_{1}-\mathrm{N}=\mathrm{N}-\Phi_{2}+2 \mathrm{O}_{2}+\mathrm{e}^{-} \rightarrow \Phi_{1}=\mathrm{O}$

$+\Phi_{2}+\frac{1}{2} \mathrm{~N}_{2}+\mathrm{NO}_{3}^{-}$(oxidative degradation).

That is, strategies to stimulate effective electron transfer capabilities of pollutant degradation and energy recycling for electrochemically steered decolorization would be top priority for environment-compatible and energysustainable treatment.

In addition, considering an energy-efficient bioprocess in common, electrochemically driven fermentation could provide more opportunities to create different redox balancing, directing myriads of metabolic routes for generation of diverse product(s) (Hongo and Iwahara 1979; Rabaey and Rozendal 2010; Rabaey et al. 2011). Regarding electron-transport-assisted bioprocesses, Rabaey and Rozendal (2010) first mentioned the term "electrofermentation." They used electrical current as alternative source of reducing or oxidizing power to guarantee different redox conditions for production. Evidently, this would be more economically feasible than fermentation using conventional substrates (e.g., glucose; Rabaey et al. 2011; Schievano et al. 2016). These all showed electron transfer-assisted bioelectrochemical activities would play crucial roles for biorefinery/bioenergy applications. As a matter of fact, many cases of fermentation are redoximbalanced; electrochemically driving fermentations provided electron transfer capabilities evolved different metabolic pathways to regulate intracellular and/or extracellular electrochemical potential(s) toward generation of value-added product(s). Thus, due to such redox potential-steered bioreactions, more energy-sustainable, substrate-saving, and product diverse-fermentation systems could be electrochemically feasible for maximization of value product formation and toxic pollutant biodegradation. However, to have system optimization for electro-fermentation, complete exploration on characteristics of MFCs was inevitably required for myriads of applications.

\section{Glimpse of microbial fuel cells}

In the recent years, He et al. (2017), Kumar et al. (2016), Hernandez-Fernandez et al. (2015), He et al. (2015), and Solanki et al. (2013) provided detailed and prolific reviews with thorough implications of microbial fuel cell (MFC) for wastewater treatment, bioenergy production, azo dye treatment, selection of electron acceptors, and exoelectrogens transfer, respectively. The concept of exoelectrogens of two dissimilatory metal reducing genera as electroactive bacteria (e.g., genomics, proteomics, and metabolomics of nanowire-generating Shewanella and Geobacter spp.; Table 1 in Kumar et al. 2016) has been well established for bioelectricity-generating applications. However, as aforementioned, sole expression of wild-type or genetically modified "superstar" bioelectricity-generating bacteria (e.g., nanowire-generating Shewanella sp.) still could not guarantee maximal electrochemically active bacteria in on-site practice. This was due to synergistic interactions in mixed cultures that would provide optimal expression of bioactivities for simultaneous organic biodegradation and production or bioenergy generation. That was simply due to mixed cultures ecologically acclimatized and electrochemically expressed mixed cultures established for maximal electron transferassociated performance. The mysteries behind this were very likely due to combined interactions (e.g., feedback compensation of intraspecific/interspecific competition or mutualism and synergistic/antagonistic to achieve maximal species diversity; Chen 2007) of microbial ecology for maximal efficiency of organic oxidation and target product formation under optimal electrochemical activities with appropriate redox balancing. In fact, such competitive interactions of mixed cultures, which generated asymmetric dynamics among species with different 
levels of electrochemical capability and combined interactions, would generally optimize species diversity for long-term coexistence (i.e., die-out of electrochemically promising, but not ecologically favorable species as ecologically stable outcomes; Briones and Raskin 2003; Chen et al. 2004, 2013a). This was why naturally dominant and ecologically stable, but not the most electrochemically active bacterium-Proteus hauseri was selected herein as a model electroactive bacterium to uncover lost episodes for complete understanding on ecologically stable MFCs. Being aware that $P$. hauseri as keystone species could play a crucial role in maintaining the electrochemically active structure of an ecological community in MFCs for stable bioelectricity generation. In fact, in ecosystems extinction of bacteria with outstanding specific functions (e.g., electrochemically active bacteria with extra metabolic burden) seemed to be evolutionarily inevitable, and thus bioaugmentation and biostimulation strategies for on-site or in situ bioremediation were regularly implemented for practical applications (e.g., bioaugmentation may be needed to prevent extinction of outstanding functioning bacteria; Chen 2007). According to Gause's law-competitive exclusion principle, metabolic burden of electrochemically active bacteria might provide condition(s) not favorable for electrochemically active bacteria to compete with other species for long-term survival (Chen and Chang 2007). That was why P. hauseri as one of stable electrochemically active bacteria and completely deciphering characteristics of $P$. hauseri-seeded mixed culture MFCs should be disclosed for system stability and operation optimization. As Bajracharya et al. (2016) mentioned, electrochemically anodic biofilm was major biocatalysts of bioelectrochemical systems (BESs) dealing with electron transport phenomena for electricity generation. Power-generating capabilities of MFC strongly depended upon whether the capacity of anodic exoelectrogens could significantly reduce mass transfer resistance and effectively enhance electron transport phenomena. According to US EPA, complete expression of essential functions of bioactivity (e.g., biodegradation of petroleum hydrocarbon contaminants) would still rely on synergistic assistance of non-functioning bioactivity for pollutant cleanup [e.g., US EPA remedial "technology"-monitored natural attenuation (MNA)]. To reach this consensus of ecological awareness for cradle-tocradle treatment, of course selecting ecologically stable and electroactive microorganisms (e.g., P. hauseri) would apparently determine whether simultaneous reductive decolorization and energy extraction in MFCs could be stably maintained for long-term operation. In particular, stable maintenance of promising electroactive consortia is also projected to increase as electroactive biofilmforming capability of comrade microbes dominant in the ecology as "keystone species" (e.g., P. hauseri) was significantly better than other species (e.g., dominant nanowire-generating bacteria like Shewanella spp.) due to swarming characteristics. Moreover, performance of electron flux in MFCs was strongly controlled by interface resistance between cell broth and biofilm and electron shuttling capabilities of redox mediators to pollutant degradation and current generation. This review tended to uncover the redox-mediating and biofilm-forming capabilities of non-nanowire-generating bacteria, for system design of MFC applications.

\section{History of Proteus genus}

Regarding Proteus genus, $P$. hauseri belonged to the family of Enterobacteriaceae, is a gram-negative Proteobacterium, but not well characterized like $P$. mirabilis. Recent findings indicated that $P$. hauseri was capable of promising bioelectricity generation and textile dye decolorization for redox-mediating applications (Chen et al. 2010). The genus of Proteus was first classified by Professor Hauser in 1885 to characterize this kind of dimorphic strains. As indicated, exploration of Proteus genus has been implemented for more than one century. Up to now, Proteus genus at least contains five species of $P$. vulgaris, P. mirabilis, P. penneri, P. hauseri, and P. myxofaciens (Pearson et al. 2008, 2011; Poore and Mobley 2003). Regarding classification, Brenner-introduced $P$. vulgaris was a heterogeneous group with at least three biogroups via DHA-hybridizations. The biogroup 1 was separated from $P$. vulgaris and the nomenclature of $P$. penneri was distinguished by negative reactions for indole production, salicin fermentation, and aesculin hydrolysis. Biogroup 2 was positive for reporter reaction of salicin and aesculin, while biogroup 3 was negative for salicin and aesculin, respectively. According to O'Hara, biogroup 3 could be composed of four distinct DNA groups, further assigned as biogroups $3,4,5$, and 6 . The new biogroup 3 was identified as $P$. hauseri due to l-rhamnose fermentation, DNase, lipase production, and Jordan's tartrate utilization (O'Hara et al. 2000). Regard to the other biogroups, they are still remained open to be further classified via characterization of other biofunctions.

As presented in the milestone history of Proteus (Fig. 1), Hauser firstly announced the genus of Proteus to the public domain. Brenner and Hickman classified more Proteus species into biogroups 1, 2, and 3 including $P$. vulgaris and $P$. penneri. On the other hand, $P$. mirabilis, a bacterium differentiated from a rod-shaped vegetative cell into an elongated and highly flagellated cell that had swarming motility, was reported as indicator in Mobley and Belas (1995). O'Hara finally defined the new biogroups 4, 5, and 6 in 2000. Recently, a new strain, $P$. hauseri ZMd44, was isolated from sewage 
of sodium hydrogen carbonate hot spring $(\mathrm{pH} \sim 7.8$, $\left[\mathrm{CO}_{3}{ }^{2-}\right] \sim 297 \mathrm{ppm},\left[\mathrm{Na}^{+}\right] \sim 187 \mathrm{ppm}$ ) in Chiao-Hsi (or Jiaoxi) on Taiwan's Lanyang Plain. This strain was predominantly selected by high-performance bacterial consortia to simultaneously decolorize monoazo dye direct orange 37 and diazo dye reactive blue 160 (Zhang et al. 2010). Although ZMd44 expressed promising capabilities for reduction of several dyes, acid black 172, acid yellow 42, and direct blue 22 were still not biodegradable. This was perhaps due to their inhibitory potency by a hydroxyl group at ortho to azo bond(s) in chemical structures. Due to the above-mentioned selection pressures, ZMd44 expressed promising capabilities in simultaneous bioelectricity generation and reductive decolorization (SBG and RD) through oxidation of secondary organic energy source via co-metabolism (Chen et al. 2010, 2013b, c). This also showed the favorable characteristics of $P$. hauseri for practical applications to contaminant bioremediation.

On the other hand, with clinical significance, $P$. vulgaris and $P$. penneri are opportunistic pathogens responsible for many urinary tract infections to humans. In fact, Proteus bacilli are widely distributed in nature (e.g., sewage, manure soil, animal faces). In particular, typical strains of Proteus own specific swarming behaviors and tended to be motile. As recent findings suggested, it was suspected that the characteristics of "swarming" mobility were strongly associated with pathogenicity to humans, as active swarming bacteria of Salmonella typhimurium exhibited greater tolerance to multiple antibiotics (e.g., polymyxin) (Kim et al. 2003). Thus, it is proposed herein that such swarming mobility very likely could have further practicability for industrial uses. Herein, we would specifically consider on flagellated (swarming, motile) variant of Proteus genus of isolated colonies with surface film (designated as $\mathrm{H}$ form of $P$. hauseri) for industrial practice.

\section{Swarming characteristics of Proteus}

Due to outstanding swarming characteristics, $P$. hauseri could function as "keystone species" to maintain electrochemically active consortia for power generation. Swarming was a kind of specific movement for many microorganisms to migrate and colonize on moist surface. It was powered by rotating of flagella present in P. hauseri, P. mirabilis, Bacillus subtilis, Pseudomonas aeruginosa, and many of other kinetic strains (Kearns 2010; Jones et al. 2004). The process of swarming was not driven by a single cell, but the population of bacteria aggregated as multicellular groups (Kearns 2010). Comparing with the motion of swimming depended on individual bacteria and the sliding spread by growth of cell, swarming bacteria move in side-by-side cell groups called raft (Fig. 2a). To trigger the swarming ability, most strains of swarming could simultaneously take place to differentiate from normal vegetable cell into elongated, flagellated, and kinetic swarming cell. In fact, dimorphic phenomenon resulting in the diversity of bacteria lawn pattern emerged in the agar plate. In particular, colonies of $P$. hauseri ZMd44 always emerged in the concentric circle pattern, on agar plate after incubation, (e.g., bull's eye pattern) (Fig. 2b). The initial incubation of ZMd44 in the plate was in vegetable form, as the bacteria were originally grown in broth medium. This type of vegetable cells was short rod-shape with the length about 1.5-2 $\mu \mathrm{m}$ long, and fimbriated around the cell, also (e.g., swimming cell) (Mobley and Belas 1995). After incubation of ZMd44, there would be a swarming

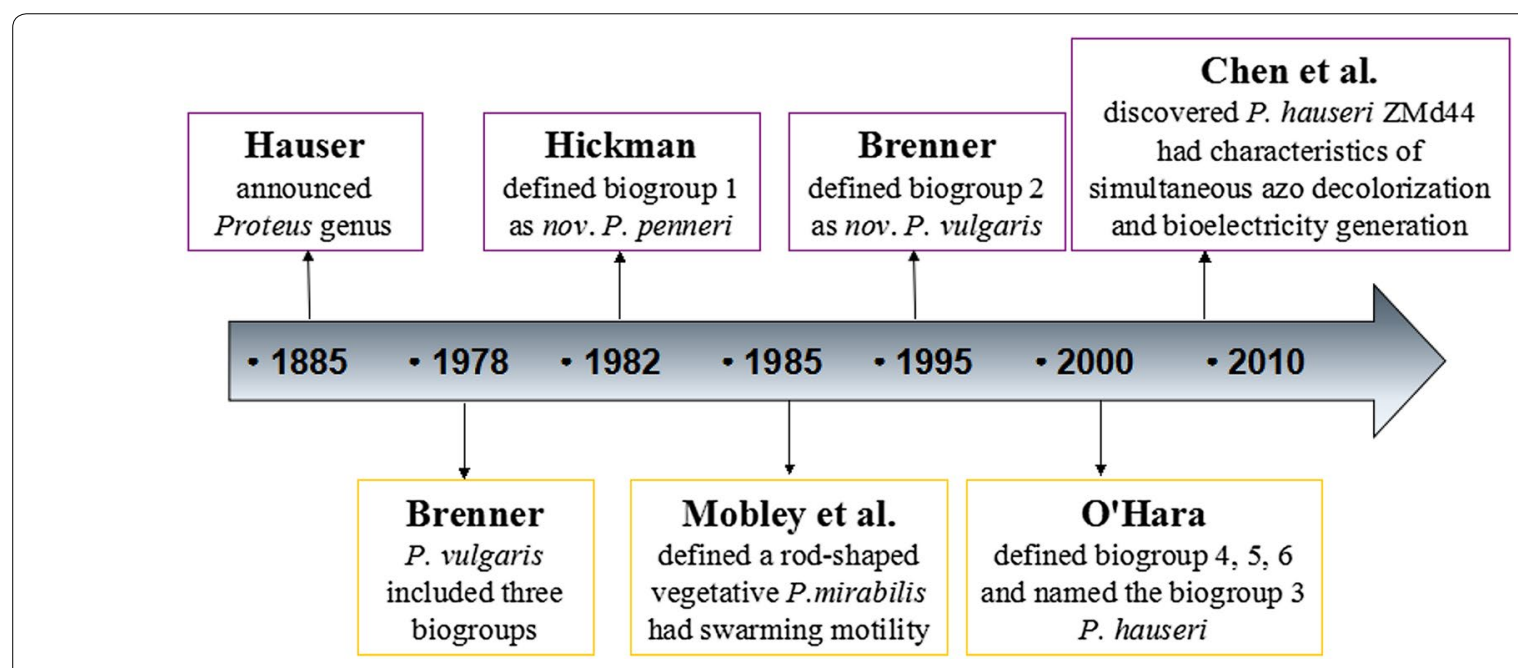

Fig. 1 History of Proteus genus-associated with findings of milestone characteristics 

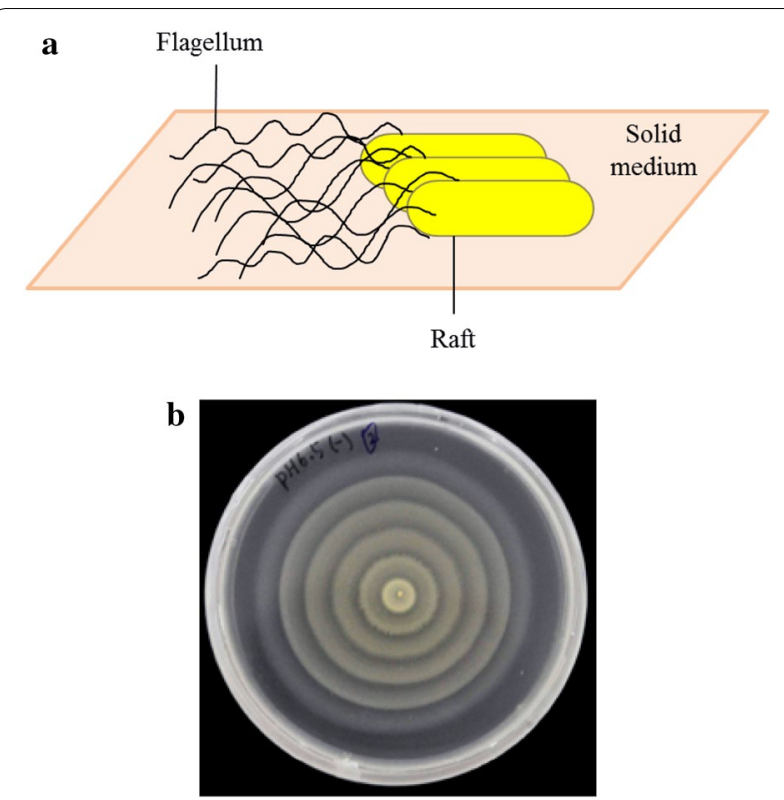

Fig. 2 a Ultrastructure model of swarming phenomenon drive by side-by-side multicellular raft. b Bull's eye pattern of Proteus hauseri ZMd44 in LB plate

lag without extension of bacteria lawn. Such a lag was still opened to be further explored, but its occurrence suggested that the vegetable cells must regulate its transcription and alter its shape to become the swarming cell. This lag was varied at about $5-8 \mathrm{~h}$ which could be shortened by increasing the inoculum density or abolished by particular mutants (Kearns 2010). After the lag, ZMd44 starts to extend and the differentiation has been done. The swimming cell elongated for several times during differentiation, and presented highly flagellated forms called swarming cell. Moreover, the raft of ZMd44 was assembled by this type of swarming cell. The raft would migrate on the surface for certain distance, and then divided back to the swimming cell. The newborn swimming cell would continue the ongoing round of differentiation, but without the lag. In fact, the cyclic lawn was resulted by repeatedly circulation of differentiation during the colonization of ZMd44.

The swarming mobility can be affect by many of environment factors. First, the most swarming strain generally requires an energy-rich, solid medium. Some of the strains like Salmonella enterica require the presence of particular supplements. P. hauseri ZMd44 could swarm on LB agar plate without additional supplements. However, a lack of energy or carbon source would delay or inhibit such swarming characteristic to be triggered. The reason was the swarming mobility was promoted by high growth rate due to the nutrient energy supports. Several strains of Proteus genus have been shown that various additional amino acids added to the minimal medium (swarming limited) agar would promote the swarming, like alanine, asparagine, and glutamic acid. This phenomenon revealed the specific amino acid could be the energy source and stimulation of swarming (Jones and Park 1967). In our previous study, copper ion significantly inhibited the swarming motility of $P$. hauseri, while Mobley et al. showed that zinc ion restrict the migration of P. mirabilis.

\section{Genomic and enzymes studies of Proteus}

Proteus, as a very special electroactive bacteria genus, genomic studies are important and necessary to understand the cell behaviors. Comparative list of Proteus strains with whole genome sequenced has been summarized in Table 1. The known coding genes for proteins or enzymes from $P$. hauseri ZMd44 (Wang et al. 2014) contained three categories of biological process (44.9\%), cellular component (23.5\%), and molecular function (31.6\%). Most of the genes were strongly associated for maintaining bacterial survival (e.g., metabolic process, membrane structure, catalytic activity). As P. hauseri ZMd44 owned resistant and tolerant characteristics of copper (Ng et al. 2013, 2014a, b), the related proteins involved the counter-defense metabolic process of copper were top-priority concern for industrial applications. From the perspectives of genomic analysis, there were only four open reading frames (ORFs) associated to copper resistance in the genome of $P$. hauseri ZMd44. These proteins were copper homeostasis protein $\mathrm{CutC}$, copper-resistance protein Crp, multicopper oxidase Mco, and repressor protein FtsI. In particular, Crp was found to be the critical protein-controlled copper resistance (Wang et al. 2014). The genomic mapping of P. hauseri ZMd44 was aligned with the control sequence of $P$. mirabilis HI4320

Table 1 Comparative list of Proteus strains with whole genome sequenced

\begin{tabular}{llllll}
\hline Strain & Accession no. & Size (Mb) & GC (\%) & Protein & Gene \\
\hline $\begin{array}{c}\text { Proteus hauseri } \\
\quad \text { AMd44 }\end{array}$ & AWX00000000 & 3.88 & 38.1 & 3147 & 3499 \\
$\begin{array}{c}\text { Proteus penneri } \\
\quad \text { ATCC } 35198\end{array}$ & ABVP00000000 & 3.75 & 37.8 & 4909 & 4997 \\
$\begin{array}{c}\text { Proteus mirabi- } \\
\quad \text { Ais HI4320 }\end{array}$ & AM942759 & 4.06 & 38.9 & 3584 & 3702 \\
$\begin{array}{c}\text { Proteus mira- } \\
\text { bilis ATCC }\end{array}$ & ACLE00000000 & 3.98 & 38.6 & 3812 & 3902 \\
$\quad \begin{array}{l}29906 \\
\text { Proteus mirabi- }\end{array}$ & CP004022 & 3.85 & 38.6 & 3335 & 3485 \\
$\quad$ lis BB2000 \\
$\begin{array}{c}\text { Proteus mirabi- } \\
\text { lis WGLW6 }\end{array}$ & AMGT00000000 & 4.05 & 39.0 & 3738 & 3820 \\
$\begin{array}{c}\text { Proteus mirabi- } \\
\text { lis WGLW4 }\end{array}$ & AMGU00000000 & 3.92 & 38.8 & 3508 & 3598 \\
\hline
\end{tabular}


to specifically locate the position of chromosomal genes. According to BASys prediction, $P$. hauseri seemed to be similar to $P$. mirabilis in genetic characteristics. As a matter of fact, Mobley's group has characterized P. mirabilis for more than thirty years (Armbruster et al. 2012, 2013). However, most of the studies only focused on the urinary tract infection caused by Proteus bacterial species with medical concerns. According to whole genomic analysis, P. hauseri ZMd44 was found to be more proteomically diverse from other Proteus genus very possibly due to its outstanding performance in biodecolorization and bioelectricity generation.

As known, the McoA-laccase was also a multicopper oxidase widely distributed among plants, fungi, bacteria (Claus 2003; Mayer and Staples 2002). The laccase was capable to catalyze the oxidation of substituted phenolic and nonphenolic compounds in oxygen-bearing conditions. One crucial property of laccase was oxidative capability toward myriads of nutrient substrates. That is, laccase was not a highly specific functioning and could be used for miscellaneous industrial applications (e.g., dye decolorization, polymers degradation, bioremediation, and organic synthesis) (Mayer and Staples 2002; Santhanam et al. 2011). For example, P. hauseri could express McoA-laccase under induction of copperstimulating condition (Zheng et al. 2013). The further enzymes analysis showed the McoA-laccase from $P$. hauseri ZMd44 more favorable to be induced in thermal and acidic environment possibly as ZMd44 was isolated from sewage of hot spring. The most appropriate condition for maximal expression of McoA-laccase was $60{ }^{\circ} \mathrm{C}$ and $\mathrm{pH}$ 2.2. Apparently, due to the inhibitory potency of copper ion to bacterial cells, excessive copper ions would repress cell growth and expression of laccase activity of $P$. hauseri ZMd44. Therefore, optimal concentration of copper ion for maximal laccase expression was determined ca. at $3 \mathrm{mM}$. Electron paramagnetic resonance (EPR) spectra confirmed that this McoA-laccase belonged to typical type 1 (T1) $\mathrm{Cu}$ site laccase and revealing that $\mathrm{Cu}(\mathrm{II})$ also played crucial roles to McoA-laccase synthesis to provided more binding sites for catalysis (Zheng et al. 2013).

In addition, several synergistic interactions of oxidoreductase-related enzymes such as laccase (EC 1.10.3.2; Dawkar et al. 2009), azoreductase (EC 1.7.1.6; Maier et al. 2004), and NADH dehydrogenase (EC 1.6.5.3; Ng et al. 2013) or cytochrome $C$ oxidase (Wariishi et al. 2002) were involved simultaneously. These enzymes all play crucial roles in dealing with decolorization of azo dyes, suggesting that decolorization seemed not simply to be driven solely by mono enzymatic catalysis or single metabolic route. However, the most significant functioning protein of azo dye decolorization seemed to be azoreductase. In Proteus genus, only P. mirabilis LAG showed the capability to decolorize the azo dyes via a NADPHdependent azoreductase (Olukanni et al. 2010). At least two azoreductases and two laccases were systematically reported in public domain, i.e., azoreductase, laccase, NADH-DCIP reductase, riboflavin reductase, lignin peroxidase (Saratale et al. 2011; Han et al. 2012).

\section{Electron-transfer-associated biodecolorization}

To elucidate electron transfer characteristics of electroactive bacteria, bacterial capabilities of reductive decolorization and power generation were both evaluated simultaneously. As electron-deficient xenobiotics, azo dyes are capable to be decolorized anaerobically via bacteria through oxygen-sensitive electrophilic oxidoreductase (e.g., laccase and azoreductase). Anaerobic treatment was feasible for treatment of dye-bearing wastewater. That is, to biodegrade such textile dyes, bacterial cells inevitably required capabilities of effective electron transfer (ET) to reduce mass transfer resistance between various extracellular aqueous phases and intracellular compartments. Although accumulation of decolorized intermediates-aromatic amines (AAs) - in cell cultures was inevitable, AAs could act as electron shuttles to feedback stimulate ET phenomena for bioelectricity generation and reductive decolorization. Apparently, both mother dyes and decolorized daughter intermediates owned electrochemical activities for redox mediation at different reduction potentials. Due to interconversion of electrical energy and chemical energy for redox reactions, bioelectrochemical systems that provided appropriate metabolic routes for optimal redox balancing would be the most energy-saving and environmentally friendly means for bioenergy and biorefinery applications. Regarding reductive decolorization of azo dyes, there are several detailed reviews mentioned about microbial degradation from diverse aspects (Pandey et al. 2007; Saratale et al. 2011). However, the systematic review for chemical structure effect on reductive decolorization was still lacking, leading to biodegradability and toxicity potency of azo dyes to be uncertain mysteries for optimal operation. Thus, this section would clarify such content of biodecolorization in term of chemical structure.

Due to diverse structures present in the synthetic dyes, changes in the chemical structures (e.g., isomers or the presence of different substituents) would significantly affect the cellular capability of reductive decolorization and bioelectricity generation. In fact, most of studies have considered color removal associated to dye classes rather than molecular features (Brown and Pagga 1986; Dohanyos et al. 1978; Hitz et al. 1978; Rodman 1971; Shaul 1991). To exhibit detailed figures of chemical structures related to reaction selectivity, it was first noted that the 
characteristics of substituents and their relative positions to azo linkage all significantly affected the performance of azo dye decolorization. Zimmermann et al. (1982) used purified Orange II azoreductase from a Pseudomonas strain KF46 to assess decolorization efficiency of Orange dyes. Evidently, the specificity of Orange II azoreductase toward azo linkage for dye decolorization was strongly dependent upon electron affinity (e.g., electron-withdrawing capability) of substituents near of azo linkage(s). Such characteristics strongly determined whether the dye was susceptible or resistant to biodecolorization. On the other hand, the hydroxyl group on the 2-position of the naphthol ring of the azo dye (e.g., 1-(4'-sulfophenylazo)2-naphthol) provides a beneficial prerequisite to assist dye decolorization. In contrast, charged groups near azo bond (e.g., 1-(2'-sulfophenylazo)-2-naphthol) significantly hinder the decolorization efficiency. Moreover, Zimmermann et al. (1982) also revealed the correlation between Hammett's substituent constant of various substituents and the decolorization rate of these azo dyes. In addition, electron-withdrawing substituent located to para position of azo bond could accelerate reductive decolorization via resonance effect as indicated in Fig. 3 indicated (Hsueh and Chen 2007, 2008; Hsueh et al. 2009).

These results pointed out that the sulfonate group produced the strongest electron-withdrawing effect resulting in the fastest rate of color removal compared to the carboxyl and hydroxyl group. In addition, when the sulfonate or carboxyl group was ortho to azo bond, the decolorization rate significantly decreased compared to the para substituent to azo bond (e.g., $p-\mathrm{MO}>o-\mathrm{MO}$ or $p$-MR_o-MR) likely due to steric hindrance near azo linkage(s) (Hsueh and Chen 2008). The similar phenomena that the more electrophilic electron-deficient azo dyes would be more easily biodecolorized were also observed in Pseudomonas luteola, Aeromonas hydrophila NIU01, Proteus hauseri, and Shewanella sp. WLP72 since they all were capable to reductively biodecolorize azo dyes (Chen et al. 2011c, 2016a, b; Hsueh and Chen 2007, 2008; Hsueh et al. 2009). That is, no matter what bacteria to be used, biodegradability or recalcitrance of azo dyes were possibly strongly associated to chemical structure of target dyes.

In addition, Squella et al. (1999) studied the steric and electronic effects on the electro-reduction of nitro group of $\beta$-nitrostyrene derivatives. When electron-donor properties of the substituent at the para position to the ethylenic double bond increased, it would make the reduction potential of nitro group more negative, meaning that the reduction of the nitro group requires more energy to be triggered. Furthermore, $\beta$-nitrostyrene derivatives was observed a linear correlation between the Hammett substituent constant $\left(\sigma_{p}\right)$ and the half-wave potential was observed. That is, the electrochemical behavior of these derivatives mainly depends on their chemical structures. Furthermore, Pasti-Grigsby et al. (1992) employed Streptomyces spp. and Phanerochaete chrysosporium to oxidatively decolorize 22 azo dyes to decipher the influence of substituents on azo dye biodegradability. As a matter of fact, the selectivity of Streptomyces spp. for removal color of azo dyes was distinct from Orange II azoreductase (Zimmermann et al. 1982). That is, it could decolorize Orange I but not Acid Orange 12 or Orange II owing to hydroxyl group adjacent to azo bond. However, $P$. chrysosporium decolorized Acid Orange 12 and Orange II more effectively than Orange I, and $P$. chrysosporium more extensively decolorized several azo dyes than Streptomyces spp. As reduced azo dyes could be reductants (i.e., electron donors), the higher electron density of azo dyes was more liable to be biodecolorized by Streptomyces spp and P. chrysosporium. Similarly, as Suzuki et al. (2001) studied, the biodegradabilities of 25 sulfonated azo dyes with different substituents correlated to decolorized efficiency with chemical structure of azo dyes were evaluated.

Compared aerobic with anaerobic decolorization of azo dyes, the higher electron density of azo dyes owning to electron-releasing substituents [i.e., hydroxyl group $(-\mathrm{OH})$, alkoxyl group (-OR) or alkyl group $(-\mathrm{R})$ ] was more easily to be oxidatively decolorized. In contrast, the lower electron density of azo dyes attached electronwithdrawing substituents [i.e., halogen $(-\mathrm{X})$, nitro group $\left(-\mathrm{NO}_{2}\right)$, carboxyl group $(-\mathrm{COOH})$ or sulfonate $\left.\left(-\mathrm{SO}_{3}{ }^{-}\right)\right]$ was more easily reductively decolorized. In addition, how and why the electronic effect and steric hindrance effect would affect the efficiency of the decolorization for azo dyes were also presented to compare abiotic photocatalysis (oxidation degradation) with biodecolorization (azo reduction) (Zhang et al. 2012), and such bioreductive phenomena were also shown for reduction of nitroaromatic compound(s) (NACs). This was likely due to azoreductase and nitroreductase both proteomic associated to identical origin in evolution (Rafii and Cerniglia 1993; Rau and Stolz 2003).

Nitroaromatic compound(s) contained strong electronwithdrawing groups (i.e., nitro group, $-\mathrm{NO}_{2}$ ) as electron deficient as azo dyes. That is, they were susceptible to reduction, and not easy to be oxidatively catabolized in aerobic environments (Ju and Parales 2010; Knackmuss 1996; Kulkarni and Chaudhari 2007). These similar reductive characteristics all supported that nitroreductases and azoreductases may originally derive from similar enzymatic systems (Hsueh et al. 2016, 2017; Misal et al. 2015; Rafii and Cerniglia 1993, 1995; Rau and Stolz 2003). 


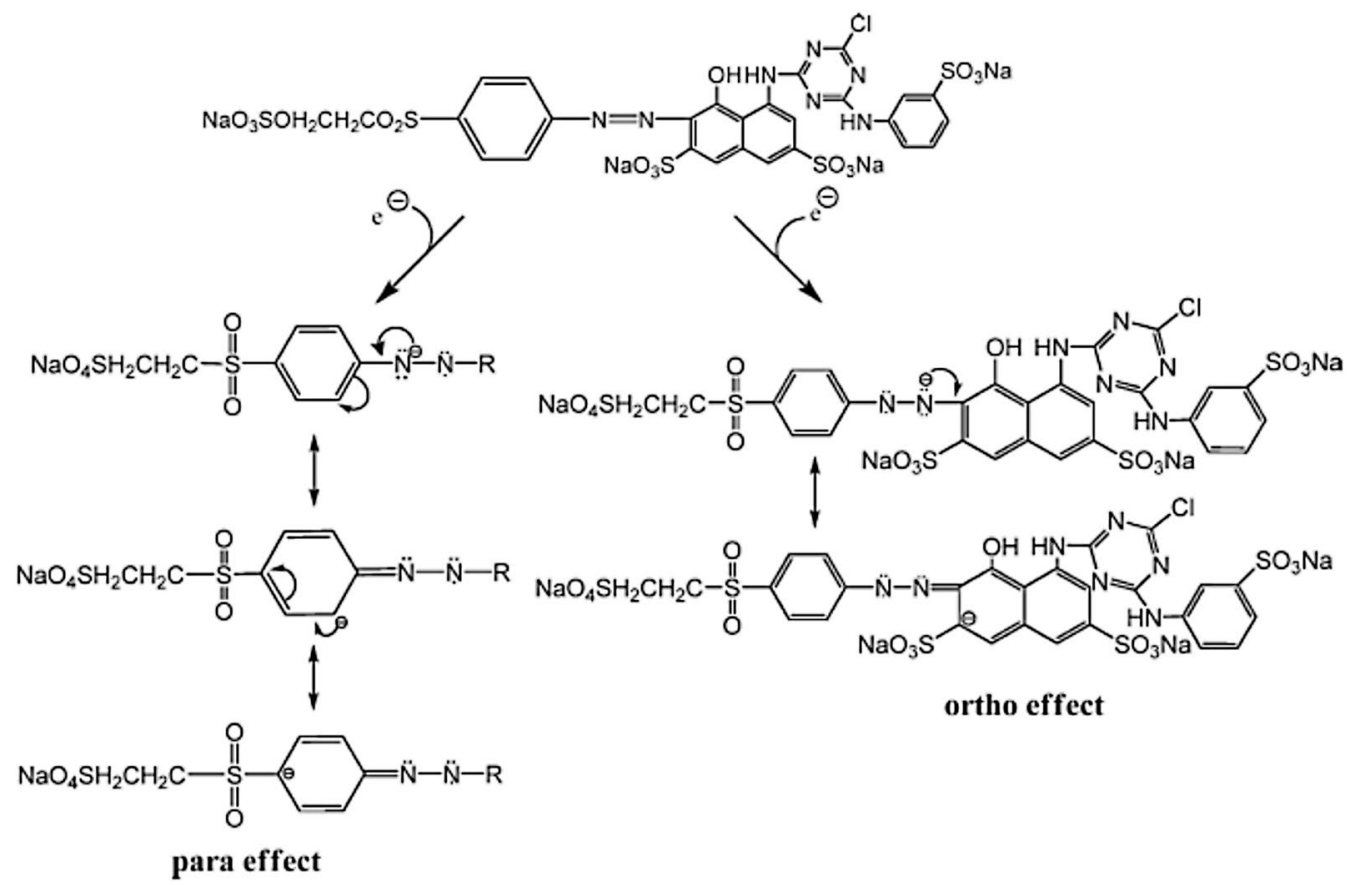

Fig. 3 Example presentation of resonance effect of RR198. The sulfonate at ortho and $-\mathrm{SO}_{2}\left(\mathrm{CH}_{2}\right)_{2} \mathrm{SO}_{4}{ }^{-}$at para to azo bond in RR198 are both high electronegativity substituents. These substituents may stabilize the negative charge present in the reduced intermediates, since azo dyes can be reduced through the inductive effect and resonance effect (Ref. to Fig. 5 in Hsueh et al. 2009)

To explore performance of electron transfer-steered reduction, Hsueh et al. (2017) had used excellent azo dye decolorizers (i.e., Aeromonas hydrophila NIU01 and Shewanella sp. WLP72) to degrade NACs [i.e., nitrobenzene (NB), 2-nitrophenol (2-NP), 4-nitrophenol (4-NP), 2-nitrotoluene (2-NT), 4-nitrotoluene (4-NT), 2,4-dinitrotoluene (2,4-DNT), 2,6-nitrotoluene (2,6-DNT)]. Evidently, both remarkable decolorizing strains also owned the promising capabilities to reduce nitroaromatic compounds. These all pointed out that bioreduction might not be so proteomically specific. Among all nitroaromatics, 2,4-DNT was the most biodegradable. As 2,4-DNT and 2,6-DNT owned two high electronegativity nitro groups, they very likely possessed higher electrophilicities within these nitroaromatic compounds. Similarly, 2-NP owned higher electrophilicity by inductive effect due to the presence of high electronegativity hydroxyl group in the proximity of nitro group. Thus, they were more biodegradable for reduction. In fact, higher electrophilicities of nitroaromatics were also capable of the more easily bioreductive characteristics. These nitroreduction phenomena were similar to reductive decolorization of azo dyes (Hsueh et al. 2009). In addition, possibly due to less steric hindrance of 2,4-DNT than 2,6-DNT, 2,4-DNT seemed to be more easily to be biodegraded than 2,6-DNT (Fortner et al. 2003).
Therefore, degradation efficiencies of both azo dyes and NACs could be affected due to their chemical structures (i.e., different substituents or positional isomers). Except for toxicity of azo dyes, NACs, or their intermediates of metabolites, the chemical structure would influence the electron density of azo bonds or nitro groups by the electronegativity of the substituents or resonance effect and the steric hindrance to affect the biodegradation efficiency. As aforementioned, the chemical structure was of great significant to affect electrophilic characteristics for oxidation or reduction. According to assessment upon azoreduction and nitroreduction, both reductive reactions were not highly enzymatic specific for redox reactions. It might suggest that electrochemical activities as well as redox potentials directly controlled electron transfer-driven bioelectricity generation. In addition, structures of aromatic diamines or aminophenol like as quinone (hydroquinone) or the positional isomer such as catechol may be suitable as the electron shuttles (Fig. 4; Chen et al. 2013a; Rau et al. 2002; Van der Zee and Cervantes 2009; Xu et al. 2014).

In summary, both nitroreduction and azoreduction were in redox similar characteristics. This could be explained by the fact that intermediate metabolites produced from azo dyes or NACs were used as redox mediators (e.g., electron shuttles) or as the reductants 

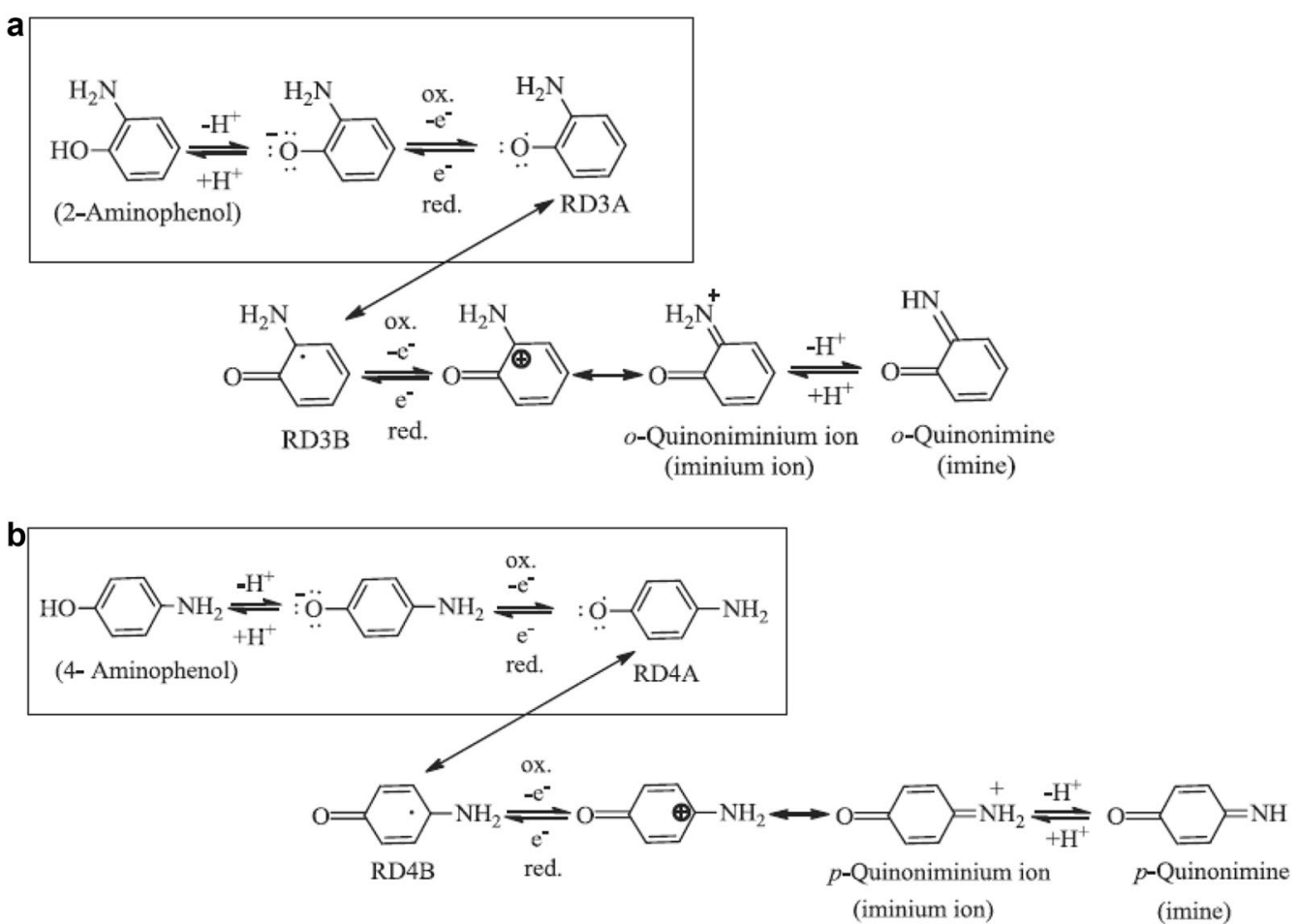

Fig. 4 a Proposed electron transfer pathways of interconversion between 2AP and o-quinonimine, b Proposed electron transfer pathways of interconversion between 4AP and p-quinonimine [Ref. Fig. 3 in Chen et al. (2013a)]

(e.g., amines or thiols) (Chang et al. 2001; Chen et al. 2010; Hsueh et al. 2014). These all enhanced the decolorization or microbial production efficiency (Chen et al. 2013a, 2016a, b; Hsueh et al. 2014, 2017; Qin et al. 2016). That was why azo dyes and NACs were electrochemically active chemicals as crucial compositions to drive electron transfer capabilities in MFCs. The comparison of P. hauseri with other electroactive bacteria on electron transport efficiency in different MFC conditions is shown in Table 2. Although P. hauseri might be not the best electroactive strain, it could still decolorize or degrade myriads of "recalcitrant" dyes for power generation. That was very likely due to competitive interaction between dye decolorization and bioelectricity generation (Chen et al. 2011b).

\section{Electron-transfer-associated applications}

When pure microbial cultures or enriched consortia with electrochemically active bacteria were stably acclimatized for maximal electrochemical expression, increases in selectivity of target metabolism redirecting carbon and electron flow away from dye decolorization to bioelectricity generation or microbial propagation toward value product generation could be bioelectrochemically regulated via reorganization of redox balancing. This was all manipulated by electron flux-driven redox potentials of chemical species that were strongly dependent upon environmental conditions (e.g., ethanol fermentation would be altered to produce acetic acid if oxygen was introduced). That is to say, with supplementation of different species of electron shuttles (ESs), electron transfer characteristics to control metabolic webs of functioning microbes would apparently be altered. With assistance of ESs, rebalancing of various reactants, intermediates, and products of redox potentials in biosystems could thus be established to catalyze myriads of bioprocesses (e.g., fermentation, bioremediation) for system engineering. As aforementioned, ZMd44 isolated from Chiao-Hsi hot spring was capable to express promising SRD and BG capabilities. Regarding reductive decolorization of azo dyes, hydroxyl substituents at ortho to azo bond apparently resisted biodegradation of azo dyes likely due to their unfavorable chemical structures for degradation to provoke biotoxicity potency to receptor cells. This failure of reductive decolorization usually led to biosorption or bioaccumulation of such dyes onto microbial surfaces and/or intracellular compartments (Chen et al. 2000; Chen 2002) via metabolism-dependent or -independent mechanisms, respectively. These would impede biodecolorization due to failure in membrane-associated transport, internal compartmentation of dye(s) into cytoplasm or onto membrane, catalysis of dye-decolorizing 
Table 2 Comparisons between Proteus hauseri and other electroactive bacteria on electron transport efficiency in different MFC conditions

\begin{tabular}{|c|c|c|c|c|}
\hline MFC conditions & $v^{\mathrm{a}}(\mathrm{mV})$ & Total $R_{\text {in }}(\Omega)$ & Power generation $\left(\mathrm{mW} \mathrm{m}^{-2}\right)$ & Refs. \\
\hline Proteus hauseri ZMd44 & $82.0-87.4$ & & & Chen et al. (2011a) \\
\hline $\mathrm{ZMd} 44+2 \mathrm{AP}$ & 115.3 & & & Chen et al. (2011a) \\
\hline$Z M d 44+3 A P^{b}$ & 104.7 & & & Chen et al. (2011a) \\
\hline Proteus hauseri ZMd44 & & 94.6 & & Xu et al. (2014) \\
\hline $\mathrm{ZMd} 44+1 \mathrm{~A} 2 \mathrm{~N}^{\mathrm{C}}$ & & 83.2 & & Xu et al. (2014) \\
\hline $\mathrm{ZMd} 44+4 \mathrm{~A} 1 \mathrm{~N}^{\mathrm{c}}$ & & 67.5 & & Xu et al. (2014) \\
\hline Aeromonas hydrophila NIU01 & & 659.9 & & Xu et al. (2014) \\
\hline NIU01 + 1A2 $N^{c}$ & & 462.7 & & Xu et al. (2014) \\
\hline $\mathrm{NIU} 01+4 \mathrm{~A} 1 \mathrm{~N}^{\mathrm{c}}$ & & 383.4 & & Xu et al. (2014) \\
\hline Klebsiella pneumoniae ZMd31 & & 463.0 & & Xu et al. (2014) \\
\hline$Z M d 31+1 A 2 N^{c}$ & & 421 & & Xu et al. (2014) \\
\hline$Z M d 31+4 A 1 N^{c}$ & & 381 & & Xu et al. (2014) \\
\hline Proteus hauseri ZMd44 & & & 21.82 & Chen et al. (2014) \\
\hline ZMd44 + Thionine ${ }^{d}$ & & & 38.84 & Chen et al. (2014) \\
\hline $\mathrm{ZMd} 44+\mathrm{MG}^{\mathrm{d}}$ & & & 50.04 & Chen et al. (2014) \\
\hline Aeromonas hydrophila NIU01 & & & 28.28 & Chen et al. (2014) \\
\hline NIU01 + Thionine ${ }^{d}$ & & & 40.87 & Chen et al. (2014) \\
\hline $\mathrm{NIU01}+\mathrm{MG}^{\mathrm{d}}$ & & & 58.86 & Chen et al. (2014) \\
\hline Klebsiella pneumoniae ZMd31 & & & 29.63 & Chen et al. (2014) \\
\hline ZMd31 + Thionine ${ }^{d}$ & & & 45.97 & Chen et al. (2014) \\
\hline$Z M d 31+M G^{d}$ & & & 67.38 & Chen et al. (2014) \\
\hline Proteus hauseri ZMd44 & & 72.17 & & Chen et al. (2015) \\
\hline ZMd44 + Thionine $^{d}$ & & 64.39 & & Chen et al. (2015) \\
\hline ZMd44 + Azure $A^{d}$ & & 43.96 & & Chen et al. (2015) \\
\hline ZMd44 + Azure $C^{d}$ & & 53.61 & & Chen et al. (2015) \\
\hline Aeromonas hydrophila NIU01 & & 299.80 & & Chen et al. (2015) \\
\hline NIU01 + Thionine ${ }^{d}$ & & 190.69 & & Chen et al. (2015) \\
\hline NIU01 + Azure Ad & & 56.01 & & Chen et al. (2015) \\
\hline NIU01 + Azure $C^{d}$ & & 86.11 & & Chen et al. (2015) \\
\hline Klebsiella pneumoniae ZMd31 & & 402.36 & & Chen et al. (2015) \\
\hline ZMd31 + Thionine ${ }^{d}$ & & 375.69 & & Chen et al. (2015) \\
\hline ZMd31 + Azure $A^{d}$ & & 71.84 & & Chen et al. (2015) \\
\hline ZMd31 + Azure $C^{d}$ & & 156.78 & & Chen et al. (2015) \\
\hline Shewanella oneidensis DSP10 & 840 & & & Biffinger et al. (2008) \\
\hline Shewanella oneidensis MR-1 ${ }^{\mathrm{f}}$ & & & 858.0 & Watson and Logan (2010) \\
\hline
\end{tabular}

a Average output voltage. $R_{\text {in }}$ internal resistance

b $900 \mathrm{mg} \mathrm{L}^{-1}$ of 2AP (2-aminophenol) or 3AP(3-aminophenol) was added

c $2 \mathrm{mg} \mathrm{L}^{-1}$ of $1 \mathrm{~A} 2 \mathrm{~N}$ (1-amino-2-naphthol) or 4A1N (4-amino-1-naphthol) was added

d $40 \mathrm{mg} \mathrm{L}^{-1}$ of Thionine, MG (malachite green), Azure $\mathrm{A}$, or Azure $\mathrm{C}$ was added

e Glucose as the nutrient in MFC

f In cubic MFC

enzymes, or mediation of electron transfer chain for azo reduction. With survey of proteomics, abundant strains nov., identified even as type strains (e.g., Rahnella and Microvirgula spp.; Han et al. 2012), could be explored; however, detailed bacterial characteristics (e.g., biological or ecological interactions between dye-degrading and/or electrochemically active capabilities) for diverse applications might be still open to be disclosed. Moreover, to explore new bacterial strains of specific characteristics, critical or hostile selection pressure(s) very different from conventional methods for species isolation should be carried out since some new metabolic functions of identified 
bacteria might still not be completely explored before. For example, as Han et al. (2012) mentioned, when capabilities of simultaneous color removal of non-azo dyes (e.g., reactive blue 198 and reactive blue 19) and azo dyes (i.e., orange I and reactive blue 160) were specifically selected, new strains of dye decolorizers (i.e., Rahnella sp. DX2b and Microvirgula sp. SH7b) were thus obtained. Inevitably, due to specific selection pressure applied for bacterial isolation, strains DX2b and SH7b might be simultaneously capable to decolorize dyes with reduction potentials ranging between -0.8 and $-1.5 \mathrm{~V}$ due to different enzymatic catalyses for color removal (e.g., laccase, NADH dehydrogenase, riboflavin reductase with synergistic aid of Fe reductase). Similarly, with different selection pressures implemented for ZMd44, membranebound and/or extracellular rather than intracellular enzymatic activities could be expressed for ZMd44 to decolorize textile dyes (Ng et al. 2014a, b). The comparisons between $P$. hauseri and other decolorizers on the efficiencies of decolorizations are shown in Table 3. It was suspected that such characteristics also synergistically reduced mass transfer and electron transport resistance for color removal. Moreover, bacterial decolorization of azo dyes are usually implemented in anaerobic conditions as azo bond(s) should be reduced with ET-aided

Table 3 Comparisons between Proteus hauseri and other decolorizers on the efficiencies of decolorizations. Cited from Hsueh et al. (2017)

\begin{tabular}{|c|c|c|}
\hline \multirow[t]{2}{*}{ Strains } & \multicolumn{2}{|c|}{$\begin{array}{l}\text { Specific decolorization } \\
\text { rate }^{\text {a }}\end{array}$} \\
\hline & $\mathrm{RBk}^{\mathrm{b}}$ & RBu $160^{c}$ \\
\hline Acinetobacter johnsonii NIUx72 & $5.97^{d}$ & $5.74^{f}$ \\
\hline Acinetobacter junii NIUY8 & $7.86^{d}$ & $3.51^{i}$ \\
\hline Aeromonas hydrophila NIU01 & $81.6^{e}$ & $16.7^{f}$ \\
\hline NIUx73 & $1.76^{\mathrm{d}}$ & $9.46^{f}$ \\
\hline YT11 & $65.89^{d}$ & $11.76^{f}$ \\
\hline Aeromonas punctata NIUP9 & $2.66^{d}$ & $4.90^{i}$ \\
\hline Enterobacter cancerogenus BYm30 & $1.62^{d}$ & $2.51^{\mathrm{f}}$ \\
\hline Exiguobacterium indicum $\mathrm{K} 4$ & $26.4^{9}$ & $7.68^{9}$ \\
\hline Klebsiella pneumoniae ZMd31 & $2.02^{d}$ & $2.71^{f}$ \\
\hline Klebsiella variicola P11 & $1.20^{\mathrm{g}}$ & $1.17^{9}$ \\
\hline Proteus hauseri ZMd44 & $3.43^{h}$ & $11.16^{f}$ \\
\hline Shewanella sp. WLP72 & $48.0^{d}$ & $62.0^{\mathrm{d}}$ \\
\hline Shewanella xiamenensis BC01 & $298.5^{j}$ & $169.4^{j}$ \\
\hline Staphylococcus gallinarum K1 & $14.11^{\mathrm{g}}$ & $2.90^{9}$ \\
\hline \multicolumn{3}{|c|}{ a Specific decolorization rate (SDR; unit: $\mu \mathrm{M} \mathrm{h}^{-1} \mathrm{ODU}^{-1}$ ) } \\
\hline \multicolumn{3}{|l|}{ b RBk5: reactive black 5} \\
\hline \multicolumn{3}{|l|}{ c RBu160: reactive blue 160} \\
\hline \multicolumn{3}{|c|}{$\begin{array}{l}\text { d-i Data adopted from Hsueh et al. (2009, 2017); Zhang et al. (2010); Chen et al. } \\
(2011 \mathrm{a}, \text { b); Han et al. (2011), respectively }\end{array}$} \\
\hline \multicolumn{3}{|l|}{ j Data adopted from Ng et al. (2014c) } \\
\hline
\end{tabular}

color removal to prevent oxygen competing with such electrons for reduction. Due to this, reductive decolorization is usually non-growth-associated, since cellular growth and color removal are competitively excluded. In contrast, for simultaneous reductive decolorization and bioelectricity generation (SRD and BG) in single-chamber MFCs, electrons used for RD and BG were competitive to each other due to nearly fixed number of electrons to be generated. Due to this competitive nature, for SRD and $\mathrm{BG}$, operation mode of reactor directly determines ET favorable toward batch (RD) or CSTR (BG) mode of operation (Hong et al. 2016).

Regarding ET capabilities, there are several bacterial characteristics proteomically functioned through electron transport chain in cells for diverse practical uses. As mentioned previously, azo dye decolorization could be carried out via ET-associated reduction. Considering applications in microbial fuel cells (MFCs), with components of electron transport from intracellular matrix to the solid-state anode, swarming behaviors of Proteus spp. could effectively form as anodophiles and/ or electrophile-like microcosm coupled with available electron shuttles (ESs) (e.g., decolorized intermediates of orange I and II; Xu et al. 2014). Thus, MFCs could effectively overcome all ET resistances for effective bioremediation (Han et al. 2015; Chen et al. 2015; Chen and Hsueh 2016). This was why bioelectrochemically aided treatment (e.g., MFCs) for pollutant biodegradation could significantly augment the performance of redoxassociated biodegradation (e.g., dye decolorization) via SBR and RD. In fact, outer membrane protein-porin expressed by ZMd44 can cross cell membrane, act as a pore, and provide a channel for ET-associated proteins for electron transport with electrochemical effectiveness (Ng et al. 2013). According to LeChatelier's principle, when an MFC at equilibrium is subjected to change(s) in operation condition(s) (e.g., significant increases of ET channels by ESs), then such a system readjusts itself to effectively counteract the applied change(s) (e.g., acceleration of electron "flow" for degradation by increases in reaction rates) for a new equilibrium state. That is, pollutant biodegradation could be effectively stimulated through operation of ES-accumulated MFCs. Although MFC-aided bioremediation could be used to stimulate dye decontamination, the main drawback of aromatic amine(s) generated in azo dye reduction was still inevitable. Therefore, two-stage operation for azo dye mineralization (e.g., combined bioanode and biocathode operation or sequencing batch reactors (SBR) based on temporal separation of anaerobic and aerobic phase; Van der Zee and Villaverde 2005) would be very possibly required. That is, anaerobic or anodic reduction of azo dye(s) should be taken place in first stage and aerobic or 
cathodic mineralization in the second stage could then be implemented to control appropriate ET capability for complete biodegradation. According to $\mathrm{Ng}$ et al. (2014a, b), $\mathrm{Cu}(\mathrm{II})$ ions could strongly restrict the swarming motility of $P$. hauser $i$ and possibly significantly decreased number of flagella per cell. With $\mathrm{Cu}(\mathrm{II})$ stress applied to change cell morphology of ZMd44 in first stage, aerobic mineralization of aromatic amines at second stage with other aerobic degraders should be efficiently implemented via biodegradation and autoxidation (Campo et al. 2011). However, from electrochemical perspectives, further studies for isolating new dye-mineralizing bacteria should still need to focus on (i) the fate of degraded and autoxidation products, and (ii) the degree of recalcitrant dye residues with environmental friendliness (Van der Zee and Villaverde 2005).

\section{Future directions and prospective}

Regarding the model EAB, ZMd44 isolated from ChiaoHsi hot spring contained several crucial biocharacteristics (e.g., dye decolorization, bioelectricity generation, ecologically stable persistence). These phenotypic properties were associated to metabolism of swarming motility for pathogenicity compared to nanowire-producing Shewanella spp. as strains with excellent ET capabilities. With MFC-aided bioremediation, extracellular products or decolorized metabolites (DMs) of P. hauseri (e.g., phenyl methadiamine; Chen et al. 2010) as ESs were capable to enhance SBR and RD (Chen et al. 2010). In addition, expression of membrane-bound redox proteins (e.g., cytochromes) of anodic biofilm of MFC was possibly the most feasible means to efficiently mediate ET between biofilm bacteria and solid anode for accelerated dye bioremediation in MFCs (Chen et al. 2011a). These all suggested that $P$. hauseri-inoculated MFC-assisted dye decolorization was possibly the most appropriate due to accumulation of DMs as exogenous ESs. Similarly, with aid of DMs as ESs, MFC-based bioremediation of recalcitrant pollutant(s) (e.g., textile dyes) would be promising due to autocatalysis of such generated intermediate(s) as exogenous mediators. However, toxicity potency of such dyes or derived intermediates to anodic biofilm in MFCs still significantly controlled MFC-aided dye bioremediation (Chen et al. 2010, 2011a). That is, selecting microbial biodegrader(s) highly resistant to toxicity potency of textile dye(s) and amine intermediates would be top-priority concern for effective MFC-assisted dye bioremediation. As a matter of fact, using MFC for dye bioremediation was favorable since DMs (e.g., 2-aminophenol, 1-amino2-naphthol) as ESs might be accumulated to significantly reduce internal resistance for ET of autocatalysis (Chen et al. 2013a, b, c; Xu et al. 2014). As a matter of fact, due to DMs as ESs, the concept of MFC-assisted dye biodegradation could be applicable for sustainable bioremediation of recalcitrant chemical(s) (e.g., azo dye(s); Chen et al. 2013c, 2016a, b). Facing the gradually polluted environment, the example of $P$. hauseri showed that even an identified bacterium might still contain crucial functioning capabilities not yet explored for bioremediation and biorefinery. Exploration upon species identified, but not well characterized for myriads of problems bring up recently, is still worthy to be implemented for sustainable development.

In addition, with aid of MFC technology (Fig. 5), fermentation systems could be in redox rebalance to have value product generation via different metabolic routes for energy recycling via augmentation of electron shuttles, reduction of electron transfer resistance, improvement of membrane for ion separation, and modification of electrode materials. Regarding electron transfer-assisted electro-fermentation (Figs. 5, 6), the supply of electric current as additional reducing equivalents would create new target reductive pathways for particular metabolic route(s) under different reduction potentials. $\mathrm{H}_{2} /$ $\mathrm{H}^{+}$and redox mediators could act as electron shuttles to stimulate oxidative/reductive fermentation of suspended microbial cultures. As capabilities of ESs strongly affected

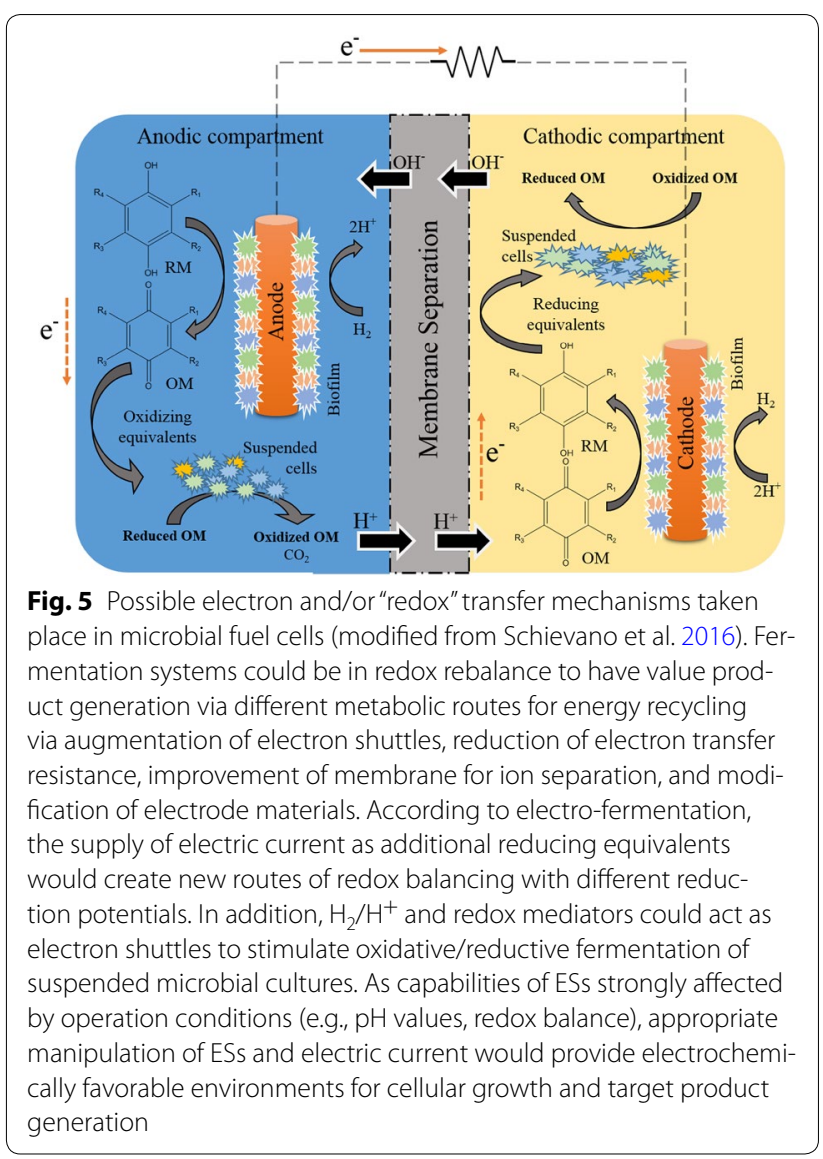




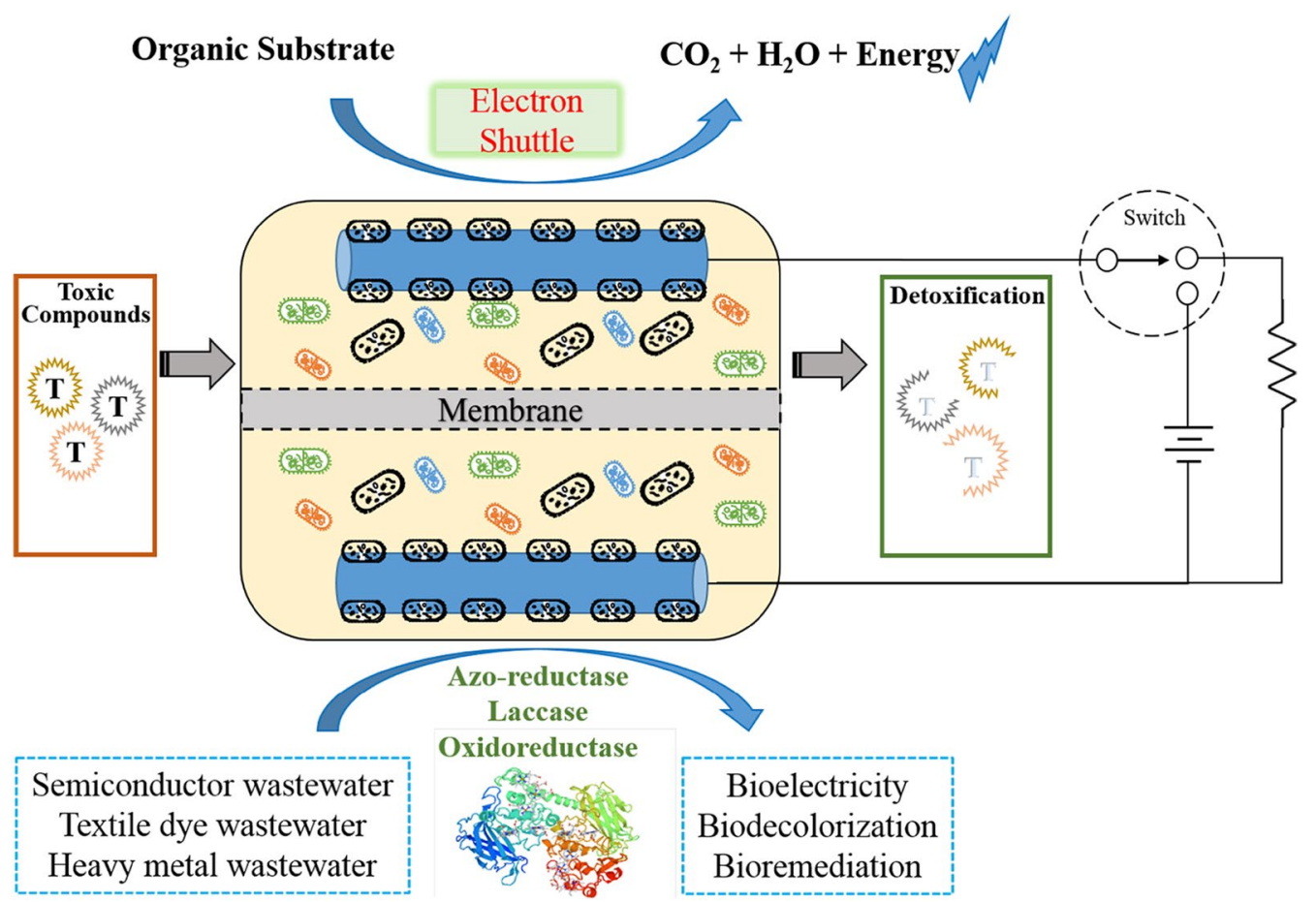

Fig. 6 Proposed microbial fuel/electrolysis cell technology via electro-fermentation for wastewater treatment. Due to applications of electric current to achieve new redox balancing, electrochemically steered wastewater treatment for bioelectricity generation, dye decolorization, and pollutant bioremediation could be obtained via such biorefinery/bioenergy-assisted bioprocesses. With applied electric current to achieve new redox balancing, electrochemically steered wastewater treatment for bioelectricity generation, dye decolorization, and pollutant bioremediation could be obtained via biorefinery/bioenergy-assisted bioprocesses

by operation conditions (e.g., $\mathrm{pH}$ values, redox balance; Chen et al. 2017a, b), appropriate manipulation of ESs and electric current would provide electrochemically favorable environments for cellular growth and target product generation. As revealed in Fig. 6, due to applications of electric current to achieve new redox balancing, electrochemically steered wastewater treatment for bioelectricity generation, dye decolorization, and pollutant bioremediation could be obtained via such biorefinery/bioenergyassisted bioprocesses. That is, MFC could be used as a tool to ripen new era of electrochemical biotechnology via electro-fermentation. Moreover, if this MFC technology moves one step forward, myriads of electrochemical bioprocesses could be achieved to have diverse product generation with assistance of external power (Fig. 6). These should be of great importance to trigger progress of MFC technology with practical value to serve global lives.

\section{Authors' contributions}

IS, CC, and BY prepared and wrote the manuscript. All authors read and approved the final manuscript.

\section{Acknowledgements}

This study is also dedicated to the memory of Dolloff F. Bishop and Henry Tabak, as most of novel concepts were initiated while the author Bor-Yann
Chen worked in National Risk Management Research Laboratory (NRMRL), US Environmental Protection Agency (EPA), Cincinnati, Ohio, U.S.A. under their mentorships.

\section{Competing interests}

The authors declare that they have no competing interests.

\section{Availability of data and materials}

The authors have agreed to provide the data and material for open access.

\section{Consent for publication}

The authors approved the consent for publishing the manuscript.

Ethics approval and consent to participate

All the authors have read and agreed the ethics for publishing the manuscript.

\section{Funding}

Financial supports (MOST106-2621-M-197-001, MOST105-2622-E-197012-CC3, MOST105-2221-E-197-022, MOST-105-2221-E-006-225-MY3) from the Ministry of Sciences and Technology, Taiwan for the project of Microbial Fuel Cells (MFCs) $)^{\text {sdg }}$ conducted in Biochemical Engineering Laboratory, C\&ME NIU and National Cheng Kung University.

\section{Publisher's Note}

Springer Nature remains neutral with regard to jurisdictional claims in published maps and institutional affiliations.

Received: 15 October 2017 Accepted: 27 November 2017

Published online: 06 December 2017 


\section{References}

Armbruster CE, Mobley HL (2012) Merging mythology and morphology: the multifaceted lifestyle of Proteus mirabilis. Nat Rev Microbiol 10(11):743-754

Armbruster CE, Hodges SA, Mobley HL (2013) Initiation of swarming motility by Proteus mirabilis occurs in response to specific cues present in urine and requires excess L-glutamine. J Bacteriol 195(6):1305-1319

Bajracharya S, Sharma M, Mohanakrishna G, Benneton XD, Strik DPBTB, Sarma PM (2016) An overview on emerging bioelectrochemical systems (BESs): technology for sustainable electricity, waste remediation, resource recovery, chemical production and beyond. Renew Energy 98:153-170

Biffinger JC, Byrd JN, Dudley BL, Ringeisen BR (2008) Oxygen exposure promotes fuel diversity for Shewanella oneidensis microbial fuel cells. Biosens Bioelectron 23:820-826

Briones A, Raskin L (2003) Diversity and dynamics of microbial communities in engineered environments and their implications for process stability. Curr Opin Biotechnol 14(3):270-276

Brown D, Pagga U (1986) The degradation of dyestuffs: part II behavior of dyestuffs in aerobic biodegradation test. Chemosphere 15:479-491

Campo P, Platten W III, Suidan MT, Chai Y, Davis JW (2011) Aerobic biodegradation of amines in industrial saline wastewaters. Chemosphere 85(7):1199-1203

Chang JS, Chou C, Lin YC, Lin PJ, Ho JY, Hu TL (2001) Kinetic characteristics of bacterial azo-dye decolorization by Pseudomonas luteola. Water Res 35:2841-2850

Chen BY (2002) Understanding decolorization characteristics of reactive azo dyes by Pseudomonas luteola: toxicity and kinetics. Process Biochem 38(3):437-446

Chen BY (2007) Revealing characteristics of mixed consortia for azo dye decolorization: Lotka-Volterra model and game theory. J Hazard Mater 149(2):508-514

Chen BY, Chang JS (2007) Assessment upon species evolution of mixed consortia for azo dye decolorization. J Chin Inst Chem Eng 38:259-266

Chen BY, Hsueh CC (2016) Deciphering electron shuttles for bioremediation and beyond. Am J Chem Eng 4(5):114-121

Chen BY, Lin CS, Lim HC (1995) Temperature induction of bacteriophage $\lambda$; mutants in Escherichia coli. J Biotechnol 40:87-97

Chen KC, Huang WT, Wu JY, Houng JY (1999) Microbial decolorization of azo dyes by Proteus mirabilis. J Ind Microbiol Biotechnol 23(1):686-690

Chen BY, Utgikar VP, Harmon SM, Tabak HH, Bishop DF, Govind R (2000) Studies on biosorption of zinc(II) and copper(II) on Desulfovibrio desulfuricans. Int Biodeterior Biodegrad 46(1):11-18

Chen BY, Chang JS, Chen SY (2004) Bacterial species diversity and dye decolorization of a two-species mixed consortium. Environ Eng Sci 20(4):337-345

Chen BY, Zhang MM, Chang CT, Ding Y, Lin KL, Chiou C-S, Hsueh CC, Xu H (2010) Assessment upon azo dye decolorization and bioelectricity generation by Proteus hauseri. Bioresour Technol 101(12):4737-4741

Chen BY, Wang YM, Ng IS (2011a) Understanding interactive characteristics of bioelectricity generation and reductive decolorization using Proteus hauseri. Bioresour Technol 102(2):1159-1165

Chen BY, Zhang MM, Chamg CT, Ding Y, Chen WM, Hsueh CC (2011 b) Deciphering azo dye decolorization characteristics by indigenous Proteus hauseri: chemical structure. J Taiwan Inst Chem Eng 42:327-333

Chen BY, Hsueh CC, Chen WM, Li WD (2011c) Exploring decolorization and halo-tolerance characteristics by indigenous acclimatized bacteria: chemical structure of azo dyes and dose-response assessment. J Taiwan Inst Chem Eng 42:816-825

Chen BY, Hong JM, Ng IS, Wang YM, Ni C (2013a) Deciphering simultaneous bioelectricity generation and reductive decolorization using mixed-culture microbial fuel cells in salty media. J Taiwan Inst Chem Eng 44(3):446-453

Chen BY, Hsueh CC, Liu SQ, Ng IS, Wang YM (2013b) Deciphering mediating characteristics of decolorized intermediates for reductive decolorization and bioelectricity generation. Bioresour Technol 145:321-325

Chen BY, Hsueh CC, Liu SQ, Hung JY, Oiao Y, Yueh PL, Wang YM (2013c) Unveiling characteristics of dye-bearing microbial fuel cells for energy and materials recycling: redox mediators. Int J Hydrog Energy 38(35):15598-15605
Chen BY, Xu B, Qin LJ, Lan JCW, Hsueh CC (2014) Exploring redox-mediating characteristics of textile dye-bearing microbial fuel cells: thionin and malachite green. Bioresour Technol 169:277-283

Chen BY, Xu B, Yueh PL, Han K, Qin LJ, Hsueh CC (2015) Deciphering electronshuttling characteristics of thionine-based textile dyes in microbial fuel cells. J Taiwan Inst Chem Eng 51:63-70

Chen BY, Ma CM, Han K, Yueh PL, Qin LJ, Hsueh CC (2016a) Influence of textile dye and decolorized metabolites on microbial fuel cell-assisted bioremediation. Bioresour Technol 200:1033-1038

Chen CT, Wu CC, Chen BY, Hsueh CC (2016b) Comparative study on biodecolorization capabilities of indigenous strains to azo dyes. Sci Discov 4:109-115

Chen BY, Ma CM, Liao JH, Hsu AW, Hsueh CC (2017a) Feasibility study on biostimulation of electron transfer characteristics by edible herbsextracts. J Taiwan Inst Chem Eng 79:125-133

Chen BY, Hsu AW, Wu CC, Hsueh CC (2017b) Feasibility study on biostimulation of dye decolorization and bioelectricity generation by using decolorized metabolites of edible flora-extracts. J Taiwan Inst Chem Eng 79:141-150

Claus H (2003) Laccases and their occurrence in prokaryotes. Arch Microbiol 179(3):145-150

Dawkar W, Jadhav UU, Ghodake GS, Govindwar SP (2009) Effect of inducers on the decolorization and biodegradation of textile azo dye Navy blue $2 \mathrm{GL}$ by Bacillus sp. VUS. Biodegradation 20(6):777-787

Dohanyos M, Madera V, Sedlacek M (1978) Removal of organic dyes by activated sludge. Prog Water Technol 10(5):559-575

EIMekawy A, Hegab HM, Vanbroekhoven K, Pant D (2014) Techno-productive potential of photosynthetic microbial fuel cells through different configurations. Renew Sust Energy Rev 39:617-627

Fortner J, Zhang C, Spain J, Hughes J (2003) Soil column evaluation of factors controlling biodegradation of DNT in the Vadose Zone. Environ Sci Technol 37:3382-3391

Han JL, Liu Y, Chang CT, Chen BY, Chen WM, Xu HZ (2011) Exploring characteristics of bioelectricity generation and dye decolorization of mixed and pure bacterial cultures from wine-bearing wastewater treatment. Biodegradation 22:321-333

Han JL, Ng IS, Wang Y, Zheng X, Chen WM, Hsueh CC, Liu SQ, Chen BY (2012) Exploring new strains of dye-decolorizing bacteria. J Biosci Bioeng 113(4):508-514

Han K, Yueh PL, Qin LJ, Hsueh CC, Chen BY (2015) Deciphering synergistic characteristics of microbial fuel cell-assisted dye decolorization. Bioresour Technol 196:746-751

Hassan H, Jin B, Donner E, Vasileiadis S, Saint C, Dai S (2017) Microbial community and bioelectrochemical activities in MFC for degrading phenol and producing electricity: microbial consortia could make differences. Chem Eng J. In press

He CS, Mu ZX, Yang HY, Wang YZ, Yu HQ (2015) Electron acceptors for energy generation in microbial fuel cells fed with wastewaters: a mini-review. Chemosphere 140:12-17

He L, Du P, Chen Y, Lu H, Cheng X, Chang B, Wang Z (2017) Advances in microbial fuel cells for wastewater treatment. Renew Sust Energ Rev 71:388-403

Hernández-Fernández FJ, de los Ríos A, Salar-García MJ, Ortiz-Martínez VM, Lozano-Blanco LJ, Toms-Alonso F, Quesada-Medina J (2015) Recent progress and perspectives in microbial fuel cells for bioenergy generation and wastewater treatment. Fuel Proc Technol 138:284-297

Hitz HR, Huber W, Reed RH (1978) The adsorption of dyes on activated sludge. J Soc Dyers Colour 94:71-76

Hong JM, Xia YF, Hsueh CC, Chen BY (2016) Unveiling optimal modes of operation for microbial fuel cell-aided dye bioremediation. J Taiwan Inst Chem Eng 67:362-369

Hongo M, Iwahara M (1979) Application of electro-energizing method to L-glutamic acid fermentation. J Agri Biol Chem 43(10):2075-2081

Hsueh CC, Chen BY (2007) Comparative study on reaction selectivity of azo dye decolorization by Pseudomonas luteola. J Hazard Mater 141:842-849

Hsueh CC, Chen BY (2008) Exploring effects of chemical structure on azo dye decolorization characteristics by Pseudomonas luteola. J Hazard Mater $154: 703-710$ 
Hsueh CC, Chen BY, Yen CY (2009) Understanding effects of chemical structure on azo dye decolorization characteristics by Aeromonas hydrophila. J Hazard Mater 167:995-1001

Hsueh CC, Wang YM, Chen BY (2014) Metabolite analysis on reductive biodegradation of reactive green 19 in Enterobacter cancerogenus bearing microbial fuel cell (MFC) and non-MFC cultures. J Taiwan Inst Chem Eng 45:436-443

Hsueh CC, You LP, Li JY, Chen CT, Wu CC, Chen BY (2016) Feasibility study of reduction of nitroaromatic compounds using indigenous azo dyedecolorizers. J Taiwan Inst Chem Eng 64:180-188

Hsueh CC, Chen CT, Hsu AW, Wu CC, Chen BY (2017) Comparative assessment of azo dyes and nitroaromatic compounds reduction using indigenous dye-decolorizing bacteria. J Taiwan Inst Chem Eng 79:134-140

Ishii S, Suzuki S, Yamanaka Y, Wu A, Bretschger O (2017) Population dynamics of electrogenic microbial communities in microbial fuel cells started with three different inoculum sources. Bioelectrochemistry 117:74-82

Jones H, Park R (1967) The influence of medium composition on the growth and swarming of Proteus. J Gen Microbiol 47(3):369-378

Jones BV, Young R, Mahenthiralingam E, Stickler DJ (2004) Ultrastructure of Proteus mirabilis swarmer cell rafts and role of swarming in catheterassociated urinary tract infection. Infect Immun 72(7):3941-3950

Ju KS, Parales RE (2010) Nitroaromatic compounds, from synthesis to biodegradation. Microbiol Mol Biol Rev 74:250-272

Kearns DB (2010) A field guide to bacterial swarming motility. Nat Rev Microbiol 8(9):634-644

Kim W, Killam T, Sood V, Surette MG (2003) Swarm-cell differentiation in Salmonella enterica serovar typhimurium results in elevated resistance to multiple antibiotics. J Bacteriol 185(10):3111-3117

Knackmuss HJ (1996) Basic knowledge and perspectives of bioelimination of xenobiotic compounds. J Biotechnol 51:287-295

Kulkarni M, Chaudhari A (2007) Microbial remediation of nitro-aromatic compounds: an overview. J Environ Manage 85:496-512

Kumar R, Singh L, Zularisam AW (2016) Exoelectrogens: recent advances in molecular drivers involved in extracellular electron transfer and strategies used to improve it for microbial fuel cell applications. Renew Sust Energy Rev 56:1322-1336

Logan BE, Hamelers B, Rozendal R, Schröder U, Keller J, Freguia S, Aelterman P, Verstraete W, Rabaey K (2006) Microbial fuel cells: methodology and technology. Environ Sci Technol 40(17):5181-5192

Maier J, Kandelbauer A, Erlacher A, Cavaco-Paulo A, Gübitz GM (2004) A new alkali-thermostable azoreductase from Bacillus sp. strain SF. Appl Environ Microbiol 70(2):837-844

Mayer AM, Staples RC (2002) Laccase: new functions for an old enzyme. Phytochemistry 60(6):551-565

Misal SA, Humne VT, Lokhande PD, Gawai KR (2015) Biotransformation of nitro aromatic compounds by flavin-free NADH azoreductase. J Bioremed Biodeg 6(2):1. https://doi.org/10.4172/2155-6199.1000272

Mobley HL, Belas R (1995) Swarming and pathogenicity of Proteus mirabilis in the urinary tract. Trends Microbiol 3(7):280-284

Mohan SV, Velvizhi G, Modestra JA, Srikanth S (2014) Microbial fuel cell: critical factors regulating bio-catalyzed electrochemical process and recent advancements. Renew Sust Energy Rev 40:779-797

Ng IS, Zheng X, Chen BY, Chi X, Lu Y, Chang CS (2013) Proteomics approach to decipher novel genes and enzymes characterization of a bioelectricitygenerating and dye-decolorizing bacterium Proteus hauseri ZMd44. Biotechnol Bioprocess Eng 18(1):8-17

Ng IS, Xu F, Ye C, Chen BY, Lu Y (2014a) Exploring metal effects and synergistic interactions of ferric stimulation on azo-dye decolorization by new indigenous Acinetobacter guillouiae Ax-9 and Rahnella aquatilis DX2b. Bioprocess Biosyst Eng 37(2):217-224

Ng IS, Zheng X, Wang N, Chen BY, Zhang X, Lu Y (2014b) Copper response of Proteus hauseri based on proteomic and genetic expression and cell morphology analyses. Appl Biochem Biotechnol 173(5):1057-1072

Ng IS, Chen TT, Lin R, Zhang X, Ni C, Sun D (2014c) Decolorization of textile azo dye and congo red by an isolated strain of the dissimilatory manganese-reducing bacterium Shewanella xiamenensis BC01. Appl Microbiol Biotechnol 98:2297-2308

Nimje VR, Chen CY, Chen CC, Jean JS, Chen JL (2009) Stable and high energy generation by a strain of Bacillus subtilis in a microbial fuel cell. J Power Sources 190(2):258-263
O'Hara CM, Brenner FW, Steigerwalt AG, Hill BC, Holmes B, Grimont P, Hawkey PM, Penner JL, Miller JM, Brenner DJ (2000) Classification of Proteus vulgaris biogroup 3 with recognition of Proteus hauseri sp. nov., nom. rev. and unnamed Proteus genomospecies 4, 5 and 6. Int J Syst Evol Microbiol 50(5):1869-1875

Olukanni O, Osuntoki A, Kalyani D, Gbenle G, Govindwar S (2010) Decolorization and biodegradation of reactive blue 13 by Proteus mirabilis LAG. J Hazard Mater 184(1):290-298

Pandey A, Singh P, lyengar L (2007) Bacterial decolorization and degradation of azo dyes. Int Biodeterior Biodegrad 59(2):73-84

Pant D Van, Bogaert G, Diels L, Vanbroekhoven K (2010) A review of the substrates used in microbial fuel cells (MFCs) for sustainable energy production. Bioresour Technol 101(6):1533-1543

Pasti-Grigsby MB, Paszczynski A, Goszczynski S, Crawford DL, Crawford RL (1992) Influence of aromatic substitution patterns on azo dye degradability by Streptomyces spp. and Phanerochaete chrysosporium. Appl Environ Microbiol 58:3605-3613

Pearson MM, Sebaihia M, Churcher C, Quail MA, Seshasayee AS, Luscombe NM, Abdellah Z, Arrosmith C, Atkin B, Chillingworth T, Hauser H, Jagels K, Moule S, Mungall K, Norbertczak H, Rabbinowitsch E, Walker D, Whithead S, Thomson NR, Rather PN, Parkhill J, Mobley HLT (2008) Complete genome sequence of uropathogenic Proteus mirabilis, a master of both adherence and motility. J Bacteriol 190(11):4027-4037

Pearson MM, Yep A, Smith SN, Mobley HL (2011) Transcriptome of Proteus mirabilis in the murine urinary tract: virulence and nitrogen assimilation gene expression. Infect Immun 79(7):2619-2631

Poore CA, Mobley HL (2003) Differential regulation of the Proteus mirabilis urease gene cluster by UreR and H-NS. Microbiology 149(12):3383-3394

Qin LJ, Han K, Yueh PL, Hsueh CC, Chen BY (2016) Interactive influences of decolorized metabolites on electron-transfer characteristics of microbial fuel cells. Biochem Eng J 109:297-304

Rabaey K, Rozendal RA (2010) Microbial electrosynthesis-revisiting the electrical route for microbial production. Nat Rev Microbiol 8:706-716

Rabaey K, Verstraete W (2005) Microbial fuel cells: novel biotechnology for energy generation. Trends Biotechnol 23(6):291-298

Rabaey K, Girguis P, Nielsen LK (2011) Metabolic and practical considerations on microbial electrosynthesis. Curr Opin Biotechnol 22(3):371-377

Rafii F, Cerniglia CE (1993) Comparison of the azoreductase and nitroreductase from Clostridium perfringens. Appl Environ Microbiol 59:1731-1734

Rafii F, Cerniglia CE (1995) Reduction of azo dyes and nitroaromatic compounds by bacterial enzymes from the human intestinal tract. Environ Health Perspect 103(5):17-19

Rau J, Stolz A (2003) Oxygen-insensitive nitroreductases NfsA and NfsB of Escherichia coli function under anaerobic conditions as lawsonedependent azo reductases. Appl Environ Microbiol 69:3448-3455

Rau J, Knackmuss HJ, Stolz A (2002) Effects of different quinoid redox mediators on the anaerobic reduction of azo dyes by bacteria. Environ Sci Technol 36:1497-1504

Ren H, Lee HS, Chae J (2012) Miniaturizing microbial fuel cells for potential portable power sources: promises and challenges. Microfluid Nanofluid 13(3):353-381

Rezaei F, Xing D, Wagner R, Regan JM, Richard TL, Logan BE (2009) Simultaneous cellulose degradation and electricity production by Enterobacter cloacae in a microbial fuel cell. Appl Environ Microbiol 75(11):3673-3678

Richter H, McCarthy K, Nevin KP, Johnson JP, Rotello VM, Lovley DR (2008) Electricity generation by Geobacter sulfurreducens attached to gold electrodes. Langmuir 24(8):4376-4379

Rodman CA (1971) Removal of colour from textile dye wastes. Text Chem Colorist 3:239

Rozendal RA, Hamelers HVM, Rabaey K, Keller J, Buisman CJN (2008) Towards practical implementation of bioelectrochemical wastewater treatment. Trends Biotechnol 26(8):450-459

Rozendal RA, Leone E, Keller J, Rabaey K (2009) Efficient hydrogen peroxide generation from organic matter in a bioelectrochemical system. Electrochem Commun 11(9):1752-1755

Santhanam N, Vivanco JM, Decker SR, Reardon KF (2011) Expression of industrially relevant laccases: prokaryotic style. Trends Biotechnol 29(10):480-489 
Saratale RG, Saratale GD, Chang JS, Govindwar SP (2011) Bacterial decolorization and degradation of azo dyes: a review. J Taiwan Inst Chem Eng 42(1):138-157

Schievano A, Sciarria TP, Vanbroekhoven K, Wever HD, Puig S, Andersen SJ, Rabaey K, Pant D (2016) Electro-fermentation-merging electrochemistry with fermentation in industrial applications. Trends Biotechnol. 34(11):866-878

Shaul G (1991) Fate of water soluble azo dyes in activated sludge process. Chemosphere 22:107-119

Solanki K, Subramanian S, Basu S (2013) Microbial fuel cells for azo dye treatment with electricity generation: a review. Bioresour Technol 131:564-571

Squella JA, Sturm JC, Weiss-Lopez B, Bonta M, Nu'ñez-Vergara LJ (1999) Electrochemical study of b-nitrostyrene derivatives: steric and electronic effects on their electroreduction. J Electroanal Chem 466:90-98

Sun J, Hu YY, Bi Z, Cao YQ (2009) Simultaneous decolorization of azo dye and bioelectricity generation using a microfiltration membrane air-cathode single-chamber microbial fuel cell. Bioresour Technol 100(13):3185-3192

Sun J, Hu YY, Hou B (2011) Electrochemical characteriztion of the bioanode during simultaneous azo dye decolorization and bioelectricity generation in an air-cathode single chambered microbial fuel cell. Electrochim Acta 56(19):6874-6879

Suzuki T, Timofei S, Kurunczi L, Dietze U, Schuurmann G (2001) Correlation of aerobic biodegradability of sulfonated azo dyes with the chemical structure. Chemosphere 45:1-9

Van der Zee FP, Cervantes FJ (2009) Impact and application of electron shuttles on the redox (bio)transformation of contaminants: a review. Biotechnol Adv 27:256-277
Van der Zee FP, Villaverde S (2005) Combined anaerobic-aerobic treatment of azo dyes-a short review of bioreactor studies. Water Res 39(8): 1425-1440

Wang N, Ng IS, Chen PT, Li Y, Chen YC, Chen B-Y, Lu Y (2014) Draft genome sequence of the bioelectricity-generating and dye-decolorizing bacterium Proteus hauseri strain ZMd44. Genome Announc 2(1):e00992-13

Wariishi H, Kabuto M, Mikuni J, Oyadomari M, Tanaka H (2002) Degradation of water-insoluble dyes by microperoxidase-11, an effective and stable peroxidative catalyst in hydrophilic organic media. Biotechnol Prog 18(1):36-42

Watson VJ, Logan BE (2010) Power production in MFCs inoculated with Shewanella oneidensis MR-1 or mixed cultures. Biotechnol Bioeng 105(3):489-498

Xu B, Chen BY, Hsueh CC, Qin LJ, Chang CT (2014) Deciphering characteristics of bicyclic aromatics - mediators for reductive decolorization and bioelectricity generation. Bioresour Technol 163:280-286

Zhang MM, Chen WM, Chen BY, Chang CT, Hsueh CC, Ding Y, Lin K-L, Xu H (2010) Comparative study on characteristics of azo dye decolorization by indigenous decolorizers. Bioresour Technol 101(8):2651-2656

Zhang Q, Jing YH, Shiue A, Chang CT, Chen BY (2012) Deciphering effects of chemical structure on azo dye decolorization/degradation characteristics: bacterial vs. photocatalytic method. J Taiwan Inst Chem Eng 43:760-766

Zheng X, Ng IS, Ye C, Chen BY, Lu Y (2013) Copper ion-stimulated McoA-laccase production and enzyme characterization in Proteus hauseri ZMd44. J Biosci Bioeng 115(4):388-393

Zimmermann T, Kulla HG, Leisinger T (1982) Properties of purified Orange II azoreductase, the enzyme initiating azo dye degradation by Pseudomonas KF46. Eur J Biochem 129:197-203

\section{Submit your manuscript to a SpringerOpen ${ }^{\circ}$ journal and benefit from:}

- Convenient online submission

- Rigorous peer review

- Open access: articles freely available online

- High visibility within the field

- Retaining the copyright to your article

Submit your next manuscript at $\boldsymbol{\nabla}$ springeropen.com 